Research Article

\title{
Numerical Analysis of the Anisotropy and Scale Effects on the Strength Characteristics of Defected Rockmass
}

\author{
Xiabing Liu $(\mathbb{D}$, Shaohui He $\mathbb{D}$, and Dahai Wang $(\mathbb{C}$ \\ Department of Civil Engineering, Beijing Jiaotong University, Beijing 100044, China \\ Correspondence should be addressed to Xiabing Liu; liuxb_1989@163.com
}

Received 22 February 2019; Revised 23 November 2019; Accepted 31 December 2019; Published 1 February 2020

Academic Editor: Timo Saksala

Copyright (c) 2020 Xiabing Liu et al. This is an open access article distributed under the Creative Commons Attribution License, which permits unrestricted use, distribution, and reproduction in any medium, provided the original work is properly cited.

\begin{abstract}
Discontinuous defect in the rockmass is a key influential factor in controlling the strength behavior, and how to estimate the anisotropic strength and scale effect on the defected rockmass is the remaining challenging focus in engineering application. In the present study, intact tuff samples cored from the Xiabeishan tunnel engineering in situ are conducted by experiment tests (i.e., uniaxial compression test, triaxial compression test, and Brazilian tensile test) to obtain the corresponding mechanical parameters. Results from the numerical simulations using the particle flow code (PFC) by the flat-jointed model (FJM) are performed to match the macroparameters from experimental results. It is observed that numerical results have good agreement with the macroscopic mechanical parameters of intact samples including UCS, BTS, triaxial compression strength, and corresponding deformation parameters. Finally, a series of uniaxial and confining compression tests are conducted by using a synthetic rockmass (SRM) method which is coupled with the discrete element method (DEM) and discrete fracture network (DFN). Then, the anisotropy and scale effects on the strength characteristics of the defected rockmass are investigated. The results show that defects have a vital effect on the failure mode and strength behavior of the rockmass in the research region. The strength parameters are changed with the specimen size. The REV size of the considered defected rockmass is regarded as $5 \times 10 \mathrm{~m}$, and this size is also influenced by the confinement level. The anisotropy of macroscopic strength parameters is found in the considered defected rockmass, whose stressstrain curves and failure modes are also discussed.
\end{abstract}

\section{Introduction}

The rockmass is made up of rock parts bounded by joints, and it is the most critical medium in underground engineering. Thus, reliable design and assessment of structural stability of underground engineering such as tunnels, slopes, and drifts require accurate estimation of the strength behavior of the defected rockmass due to the defects at different scales including the microdefects at the grain scale, veins in the experiment test rock specimen, cemented or weakened cemented fractures at the rock block scale, and block formation at the overall rockmass scale [1]. These defects may influence the rockmass strength and failure mode. The existence of defects at different scales usually causes a lower strength of the defected rockmass, and the mechanical behavior of the defected rockmass differs from that of the intact rock. Figure 1 shows that the rockmass containing defects at different scales has continuous and critical orientation (i.e., oriented parallel to the critical shear stress on defects), and the UCS of the defected rockmass is variable [2].

Accompanied by the development of civil projects and underground space exploration, the accurate estimation of rockmass strength is important and valuable for engineering applications and has become a research focus over the past decades. For the research background in this article, with the increasing high-speed railway projects in China, lots of surrounding rockmass problems are encountered, such as the scale effect and excavation stability of the defected rockmass. In this article, the term "defected rockmass" is assumed to weaken cemented and close discontinuities at the rock block scale such as veins, fractures, and weakened 


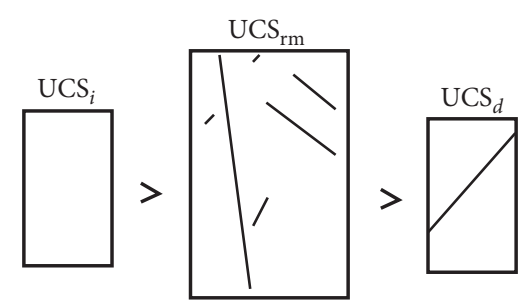

FIGURE 1: Concept of the UCS variability of rockmass specimens due to the different density and orientation of defects [3]. UCS intact rock UCS; $\mathrm{UCS}_{d}$ : defected rock UCS; $\mathrm{UCS}_{\mathrm{rm}}$ : rockmass UCS.

cemented joints that may influence the strength of rockmass. The intact rock matrix refers to a laboratory specimen that does not contain any strength-dominating defects.

Extensive researches are conducted for further understanding the influence of discontinuous defects. Most of them $[4,5]$ assume that the defected rockmass is isotropic and homogeneous. However, engineering applications have proved that this assumption is not always reasonable. The most direct approach to obtain the strength and failure mode of the defected rockmass is the laboratory experiment and large-scale in situ test. The mechanical parameters of the intact rock at a laboratory scale are relatively straightforward, but challenges of determining rockmass strength are encountered in practical engineering due to the rockmass containing defects within different scales. It has been noted that results of intact rock samples from laboratory tests are commonly inaccurate for the engineering applications, and the large-scale in situ tests for the rockmass are impossible.

Empirical approaches based on the characterization systems such as the geological strength index (GSI) [6], Q system [7], and rockmass rating (RMR) [8] are the most popular methods in estimating the rockmass strength. These empirical approaches are developed from engineering experiences. Despite all this, the accurate estimation of rockmass strength is still smeared on account of the complex features of defects (e.g., defect density, roughness, and direction) and subjective judgment results of the rockmass classification [9]. Because these types of methods make use of classification systems based on engineering cases [10-12], they often give too conservative and uncertainty estimations.

The scale effect on the defected rockmass has been well demonstrated in laboratory tests. Its strength varies with the increasing specimen size until the strength becomes independent of the specimen size [3]. Figure 1 schematically shows how the defected rockmass strength varies with different sizes between the intact rock matrix strength and the strength of the specimen failed along a single continuous defect. A common concept for understanding the UCS variability of defected rockmass specimens is the representative element volume (REV), which is the size at which the tested samples contain adequate defects for determining a consistent "average value" under several repeat tests [13]. This concept is usually used to determine whether the defected rockmass can be treated as an equivalent continuum medium. The concept of REV provides an essential implication to select the analysis methods and tools for engineering applications.
With the development of computer technology, numerical implementation becomes an important way to study and understand the strength and failure mode of the rockmass. Recent developments of the discrete element method (DEM) are an efficient approach for studying the rockmass mechanical behavior [14-16]. The DEM treats the rockmass as assemblies of intact parts and defects separately. The interaction between intact parts and defects during the loading process can be explicitly presented in comparison with these equivalent continuous methods such as the FEM. Therefore, the strength behavior of the rockmass can be accurately estimated by the DEM [17].

Gaining a quantitative understanding of the rockmass strength in this study is carried out using $\mathrm{PFC}^{2 \mathrm{D}}$, developed by Cundall [18]. $\mathrm{PFC}^{2 \mathrm{D}}$ is a two-dimensional DEM used to solve a broad range of discontinuous deformation problems in geoengineering and other fields. $\mathrm{PFC}^{2 \mathrm{D}}$ conducts a plane analysis on geomaterials. The geomaterials are simulated as assemblies of bonded particles (i.e., disks in 2D), which are used to simplify the contact search process. These particles move independently and can interact with contact behaviors at the contact points. The contact behaviors are described by the contact models, which can simulate the movement and deformation of particles. The parallel-bonded model (PBM) [19] is a commonly adopted contact model in previous studies. The position and velocity of each particle are updated based on solving the movement equations and force-displacement laws tied to the movements and interactions at contacts within these particles. Particle distribution, contact model, and related microproperties are assigned by users [20]. The mechanical response is simulated by loading or unloading the rigid frictionless walls located at the external boundary, which can avoid the complex constitutive model description in equivalent continuous mechanical methods.

The PBM can be used to represent the mechanical behavior of rock materials. For decades, numerous studies indicate that this numerical implementation has distinct merits on understanding and studying the microcracking mechanism of initiation, coalescence, and propagation of rock materials [21-23]. However, the PBM has some intrinsic problems in capturing the mechanical behavior of real rocks [24-26]. The newly developed flat-jointed model (FJM) [27] adopts notional elements of contact pieces to simulate the irregular minerals in rocks, and the insufficiency of the PBM in simulating rocks is improved. In this article, the FJM is adopted to simulate the intact rock.

To simulate the macroscopic mechanical behavior of defects by the DEM, Mas Ivars [28] developed the smoothjointed model (SJM) logic which describes the slip behavior between the particles. The synthetic rockmass (SRM) method linked with the bonded-particle model (BPM), and the SJM has become an interesting issue to study the defected rockmass since it emerged. As with other DEM codes, the PFC deals with the interaction between intact parts and defects. The rock bridges can be breakable compared with the other DEM codes (e.g., UDEC). Several researchers have investigated the scale effect on rockmass strength using the SRM method such as those by Esmaieli 
et al. [29], Pierce et al. [30], Elmo and Stead [31], Wang et al. [32], Zhang and Stead [33], and Vallejos et al. [34], which have simulated the increasing specimen size of the jointed rockmass leading to an apparent decrease in the strength. Their results indicate that the SRM method is valid and suitable for studying the strength behavior of the rockmass. The results reported by Wang et al. [32] and Poulsen et al. [35] suggest that defect density with the increasing specimen size as well as the loading conditions contributes to the rockmass strength.

However, most of the previous studies about the rockmass strength behavior are conducted in the uniaxial condition and have limitations on the confining rockmass strength behavior. It should be noted that the loading condition also has a substantial influence on this issue [3]. Moreover, due to the drawback of the PBM currently used, the tensile strength of the intact rock matrix cannot be accurately calibrated [19]. Hence, the objective of this paper is to establish a more in-depth understanding of the anisotropy and scale effects on the defected rockmass due to the impossible application of large-scale in situ and laboratory tests. Based on a real engineering background in China, this study intends to provide a good understanding of the defected rockmass in engineering applications. In the following, a discrete fracture network (DFN) is firstly generated based on information collected by field investigations at the Xiabeishan tunnel in Taizhou City, Zhejiang Province, China; then, the microproperties of the intact rock and defects are, respectively, calibrated to match the laboratory results; finally, the DFN model are coupled into the intact rock based on $\mathrm{PFC}^{2 \mathrm{D}}$, and the defected rockmass strength characteristics are taken up by the SRM approach.

\section{Research Background}

Discontinuous weakness defects in the rockmass, which may induce a complex mechanical behavior such as the nonlinear and anisotropic traits, are widely distributed in engineering applications in a very mazy manner. For understanding the anisotropy and scale effects on the defected rockmass, the defect information is collected by field investigations at the Xiabeishan tunnel, which is located in Taizhou City, Zhejiang Province, China. This tunnel is a part of the newly constructed high-speed railway from Hangzhou City to Taizhou City, and it is a four-lane tunnel with the excavation span reaching about $26 \mathrm{~m}$ and excavation area reaching about $350 \mathrm{~m}^{2}$. Due to the large excavated span of the Xiabeishan tunnel, the sequential excavation method is inescapable to consider in the design phase. Sequential excavation is a complex loading and unloading process in underground engineering, which changes the state of stresses and redistributes loadings in the surrounding rockmass. Applications of the SEM may cause damage or even failure in the surrounding rockmass. Therefore, some problems of the rockmass stability during the sequential excavation may be encountered. To ensure the stability of excavation, indispensable presupport and support measures should be installed in each step. Therefore, understanding the mechanical behavior of the rockmass is crucial for tunnel stability. Empirical methods [6] provide a preliminary understanding of the rockmass behavior, but they are always rude and subjective estimation methods. On account of the existing defects in the tunneling region, it is necessary to conduct a detailed analysis for understanding the rockmass strength behavior. In this paper, the middle part in the Xiabeishan tunnel is chosen as the studying region where the rockmass contains two defect sets with different persistence. The SRM method is used by coupling the discrete fracture network (DFN) into the intact rock based on $\mathrm{PFC}^{2 \mathrm{D}}$. Discontinuous defects are defined as weak cemented and closed joints, and the microflaws in the intact rock are neglected. In Section 3, a detailed procedure is introduced, but the DFN model representing the in situ distribution must be prepared first.

To understand the defected rockmass strength behavior, the authors establish the DFN model in Figure 2 by the following procedure:

(1) Through field outcrops in the tunneling region (see Figure 2), the geological-structure information including the dip, dip direction, trace length, and defect spacing is recorded.

(2) Based on the statistical analysis of the geometric information of defects, the probability model and its parameters of each defect set are determined. According to the scene survey result, as shown in Figure 2, there are two sets in the selective region, and Table 1 shows the geometrical parameters and probability model of each defect set. As this research work is a two-dimensional analysis tool of $\mathrm{PFC}^{2 \mathrm{D}}$ used, the defects are represented by lines in the 2D plane; thus, the dip, trace length, and spacing of defects follow one particular probability statistical function by conducting a statistical analysis of the information from the results of the field investigation. Nonetheless, the dip direction is not listed in Table 1; the 3D statistical DFN model considering the full information should be used for modeling the defected rockmass in future research.

(3) According to the information in Table 1, the DFN is generated by a Monte Carlo approach [36]. The density and number of defects in the simulated regions are, respectively, determined; then, the centre coordinate, dip angle, and length of each defect are generated by the FISH language in the PFC based on the Monte Carlo approach, and the generated DFN model is similar to the defect distribution captured from the in situ exposure.

(4) The scale, number, and other parameters of each defect set are examined carefully. The probability model of the DFN is checked if the parameter of the defect set does not match the measured data. Then, the DFN should be revised by the above-mentioned steps.

As shown in Figure 2, the basic DFN model is $30 \times 30 \mathrm{~m}$ in this study. It is similar to the defect distribution trait captured in the in situ outcrop area. By treating this basic 

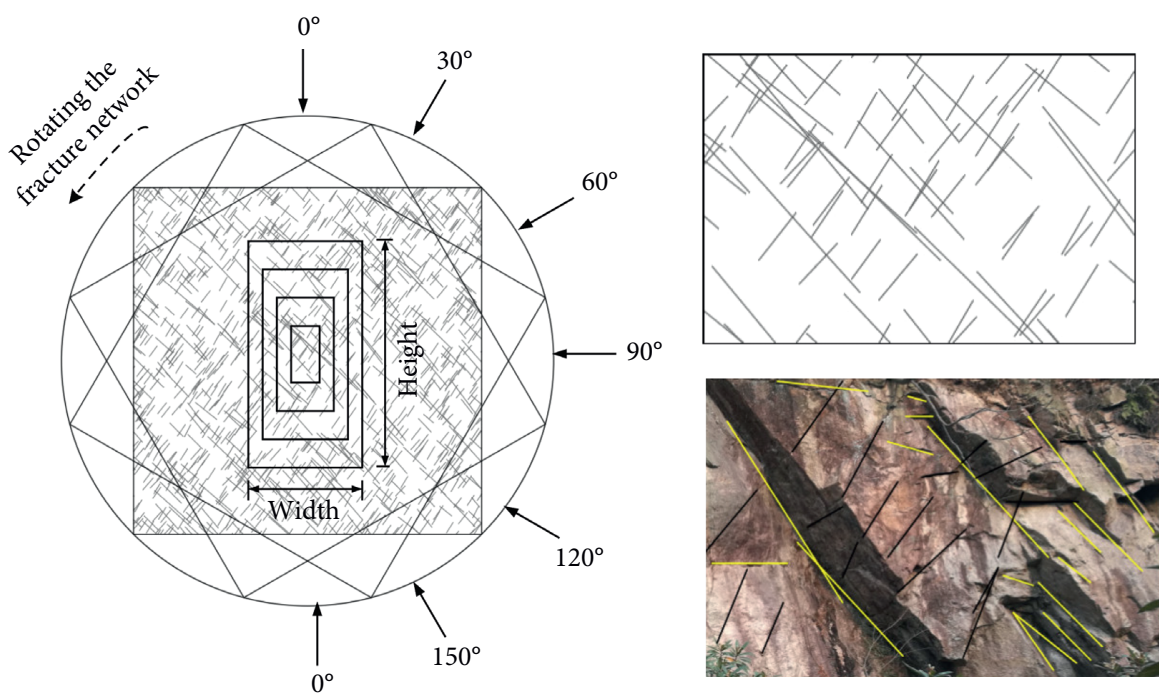

FIGURE 2: Generation of the discrete fracture network (DFN) for the rockmass.

TABle 1: Defect sets and input data for generating the DFN.

\begin{tabular}{|c|c|c|c|c|c|c|c|c|}
\hline \multirow[b]{2}{*}{ Set } & \multicolumn{3}{|c|}{ Dip } & \multicolumn{3}{|c|}{ Length } & \multicolumn{2}{|r|}{ Space } \\
\hline & Mean value $\left(^{\circ}\right)$ & $\begin{array}{l}\text { Distribution } \\
\text { function }\end{array}$ & $\begin{array}{c}\text { Standard } \\
\text { deviation }\left({ }^{\circ}\right)\end{array}$ & $\begin{array}{c}\text { Mean } \\
\text { value }(\mathrm{m})\end{array}$ & $\begin{array}{l}\text { Distribution } \\
\text { function }\end{array}$ & $\begin{array}{c}\text { Standard } \\
\text { deviation }\left({ }^{\circ}\right)\end{array}$ & $\begin{array}{c}\text { Mean } \\
\text { value }(\mathrm{m})\end{array}$ & $\begin{array}{l}\text { Distribution } \\
\text { function }\end{array}$ \\
\hline Set1 & 54 & Normal & 4.5 & 1.2 & Normal & 0.25 & 0.75 & Normal \\
\hline Set2 & 44 & Normal & 8.5 & 1.7 & Negative exponent & - & 1.8 & Negative exponent \\
\hline
\end{tabular}

DFN, a series of numerical specimens are prepared to investigate the anisotropy and scale effects on the defected rockmass.

\section{Simulation Approach for Studying Defected Rockmass Strength}

3.1. Generation of SRM Specimens. The defected rockmass of the Xiabeishan tunnel is generated by the SRM method, which defines the rockmass as assemblies of defects embedded into the intact rock in $\mathrm{PFC}^{2 \mathrm{D}}$. In an SRM model, the mechanical response is determined by both the input properties of the intact parts and defects in the rockmass. The intact parts are simulated by the PBM, and the defects are simulated by the smooth-jointed model (SJM), as shown in Figure 3(a) (the red lines between particles are the contacts representing intact parts, i.e., FJM contacts in this article, and the magenta lines are the SJM contacts). The SJM, simulating the slip and interaction behaviors of defects with dilation regardless of the local particle contact orientations along with the contact interface, is an intrinsic property between two particles at each contact [28]. Figure 3(b) shows that the SJM defines a specific frictional slip along a given plane with bonded or unbonded properties, which eliminates the riding effect over the disks and simulates a real slip behavior compared with the bond move method [37]. Each pair of particles may overlap and slip past, and the SJM contacts can be assigned with tensile and shear bonded strength to simulate the bonded slip behavior. A detailed description of the newest SJM is introduced in the PFC user manual [20]. The bonded-particle model simulating the intact rock matrix is introduced in Section 3.2.1.

The generation procedure of an SRM specimen is presented as follows: first, the DFN is generated according to the statistical information of defects obtained from the field mapping after revision; the DFN is inserted into an intact rock model, and the FJM contacts in these locations are removed after assigning the SJM contacts; then, the microproperties of the intact rock matrix and defects can be, respectively, calibrated; finally, loading or unloading on the numerical specimens results in cracking initiation, propagation, and merging behavior so that the mechanical behavior of the rockmass can be captured to supply understanding and reference for engineering applications.

A lot of SRM specimens are generated by rotating the basic DFN prepared in Section 2. Figure 2 shows the schematic diagram of studying the anisotropy and scale effects on the defected rockmass. The centre of the basic DFN is selected as the rotating point, and the rotating degree is in the range of $0^{\circ} \sim 150^{\circ}$ with an increment angle of $30^{\circ}$ (see Figure 2). The rotated DFNs are symbolized as DFN0, DFN30, DFN60, DFN90, DFN120, and DFN150, respectively (e.g., DFN90 means that the basic DFN is rotated $90^{\circ}$ ). Then, the SRM specimens with the height-to-diameter ratio $2: 1$ are generated from these rotated DFNs. The model width is in the range of $2-10 \mathrm{~m}$ with an increment size of $1 \mathrm{~m}$. In all, specimens with six different defect directions are prepared for sequential analysis. 


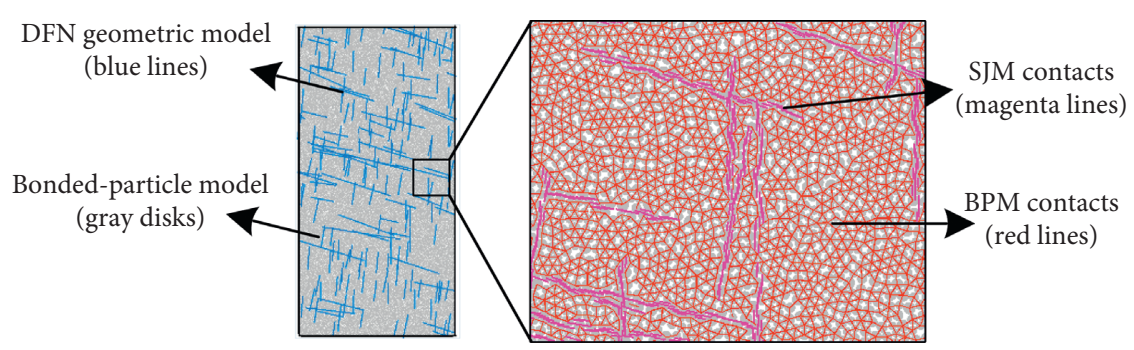

(a)

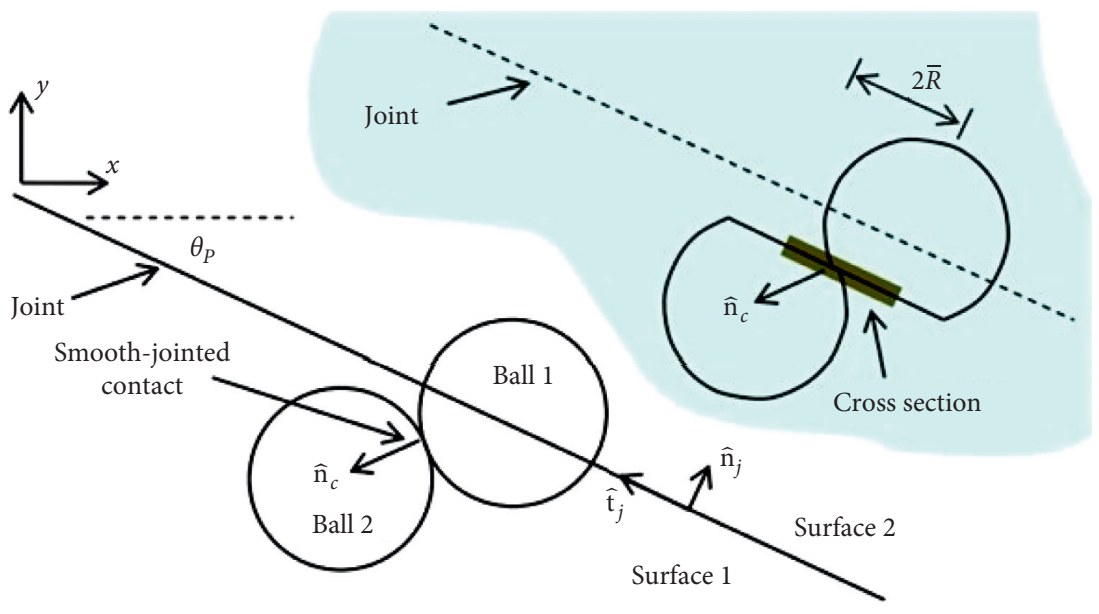

(b)

FIGURE 3: Synthetic rockmass specimen and the smooth-jointed model logic. (a) Overview of an SRM specimen. (b) Contact behavior of the smooth-jointed model (from Mas Ivars et al. [28]).

\subsection{Intact Matrix Rock Simulation}

3.2.1. Choosing Contact Model for Modeling Intact Matrix Rocks. There are several contact models for simulating the rock or rock-like materials, such as the parallel-bonded model (PBM) developed by Potyondy and Cundall [19]. As mentioned in Section 1, recently extensive studies indicate that when using the PBM in modeling the response of real rocks, some intrinsic deficiencies are encountered [24]: (1) the ratio of uniaxial compression strength to tensile strength (UCS/TS) is in the range of 3-7, which is inauthentic low compared with experimental results, (2) the confining strength envelope is linear, and (3) the internal friction angle is excessively lower compared with the lab test results. The real rock usually exhibits a UCS/TS ratio of 10-20 and a nonlinear strength envelope with a high internal friction angle in lab tests. The UCS/TS ratio plays a vital role in the fracturing process and mechanical behavior of rocks [24]. Ghazvinian conducted a series of direct shear tests of the rock joint, which indicated that the tensile strength of the rock matrix had a significant effect on the shear strength behavior of the jointed rockmass [38]. Hence, the tensile strength affects the tension and compression behaviors of real rocks. The role of the tensile strength of the intact parts in the rockmass is neglected in previous studies. A more accurate presentation of the intact parts' tensile strength in the rockmass should be improved in the research issue of rockmass.

The flat-jointed model (FJM) developed by Ptyondy [27] can effectively improve these deficiencies of the PBM in describing the material response of real rocks, especially the UCS/TS ratio and nonlinear strength envelope. Figure 4(a) presents a schematic diagram of the FJM. Each contact is defined as a local contact surface with several contacting pieces, where these contacting pieces of the notional contact surfaces are called notional elements. These notional elements are lines in the 2D model and disks in the 3D model, and they have a specific length or area, which enables regular particles performing as irregular polygonal grains. These notional polygonal grains can show the structure characteristics of real rocks (e.g., real rocks consisting of irregular minerals), which results in a more reasonable macromechanical simulation due to the strong interlocking interaction between grains. Such notional elements of contacting pieces can be installed with bonded or unbonded properties and interact at the activated FJM contacts between grains. The force-displacement laws of notional elements are described as follows [20].

The notional element with bonded properties is presented in the linear and elastic contact behavior until the element contact stress reaches the predefined bonded strength. The damage of the bonded element can induce a tensile- or shear-cracking way. As can be seen in Figure 4(b), when the trial element normal stress $\sigma_{\max }^{e}>$ the bond threshold strength, i.e., the tensile strength $\sigma_{t}$, the bond is broken as a tensile mode, and the bonded state is modified to the unbonded state. Based on the strength envelope curve, the Mohr-Coulomb criterion with a tension cutoff is defined for the shear strength: $\tau_{c}=\sigma_{c}-\bar{\tau} \tan \phi$, where $\sigma_{c}$ is the 


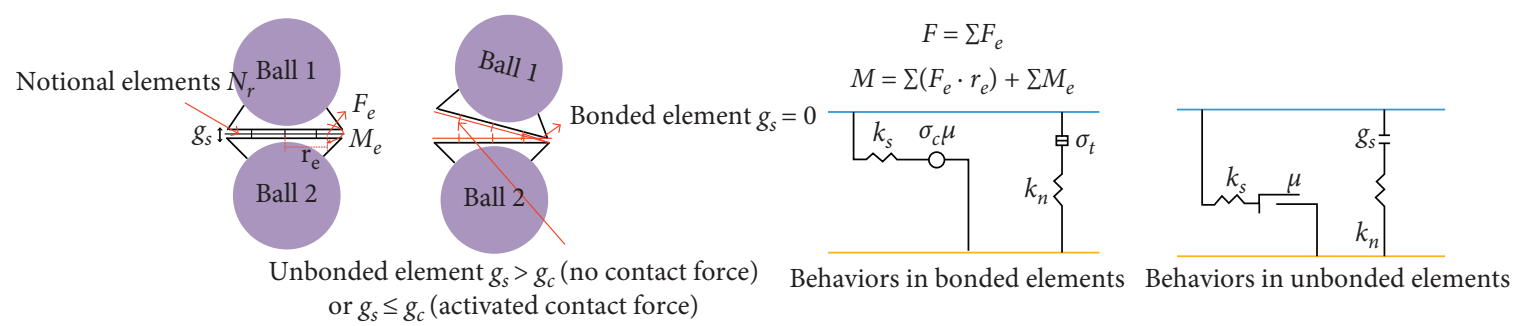

(a)

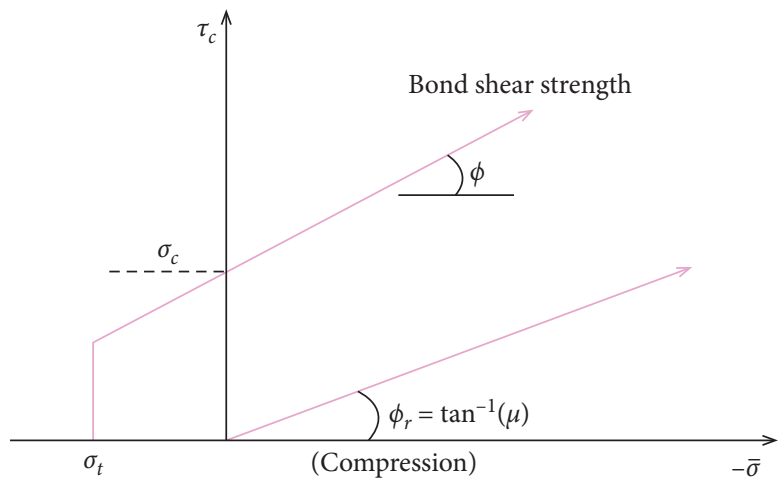

(b)

FIGURE 4: Flat-jointed model (FJM) for simulating the intact rock (modified from Itasca [20]). (a) Schematic diagram of the FJM. (b) Strength envelope curve of the bonded and unbonded elements. $k_{n}$ and $k_{s}$ are the normal stiffness and shear stiffness, respectively; $\sigma_{c}$ is the bonded cohesion strength; $\mu$ is the frictional coefficient; $g_{s}$ is the contact interface gap; $g_{c}$ is the contact gap; $\sigma_{t}$ is the tensile strength; and $F_{e}$ and $M_{e}$ are the force and moment of the notional elements, respectively.

bonded cohesion strength and $\phi$ is the friction angle. When the trial element shear stress $\tau_{\max }^{e} \leq \tau_{c}$, the element shear stress is maintained at $\tau_{\max }^{e}$; otherwise, the bond is broken as a shear mode, and then the bond state is modified to the unbonded state, and the residual friction shear strength $\tau_{r}$ shows the effect: $\tau_{r}=-\bar{\sigma} \tan \phi_{r}$, where $\phi_{r}$ is the residual friction angle.

The notional element with unbonded properties is presented in a limiting shear strength determined by the Mohr-Coulomb criterion (see Figure 4(b) and PFC user manual [20]). In this case, the tensile strength $\sigma_{t}$ is set as zero, and the normal strength is given by

$$
\bar{\sigma}= \begin{cases}-k_{n} g_{s}, & g_{s}<0, \\ 0, & g_{s} \geq 0 .\end{cases}
$$

The shear stress $\tau_{r}$ is controlled by the Mohr-Coulomb criterion:

$$
\tau_{r}= \begin{cases}-\bar{\sigma} \tan \phi_{r}, & \bar{\sigma}<0, \\ 0, & \bar{\sigma}=0,\end{cases}
$$

where $\phi_{r}$ is the residual friction angle (i.e., the friction coefficient $\mu$ ) and $g_{s}$ is the contact interface gap. When the trail element shear stress $\tau_{\text {max }}^{e} \geq \tau_{r}$, the shear stress remains as $\tau_{\max }^{e}$; otherwise, the shear stress is given by $\tau_{\max }^{e}=\tau_{r}$. The tensile or shear crack does not occur in the type of unbonded element.
Each contact interface can be regarded as several notional elements of contact pieces, and the bonded cracking behavior can occur in any notional element. Therefore, these notional elements can be in a bonded or unbonded state over the contact interface. Even if the bond element is broken, the rotational resistance of the contact interface still exists and does not disappear compared with the PBM. $\mathrm{Wu}$ et al. [24] suggested that the real rocks simulated by the FJM have a better consequence in matching the UCS/ TS ratio and the nonlinear strength envelope. The experimental results show that the UCS/TS ratio of the Xiabeishan tuff is 10-18. Hence, the flat-jointed model (FJM) is used to simulate the material response of the Xiabeishan tuff.

It has been accepted that the microproperties used in the PFC have no direct relationship with the mechanical parameters (i.e., elastic modulus $E$, Poisson's ratio $v$, tensile strength $\sigma_{\mathrm{TS}}$, uniaxial compression strength $\sigma_{\mathrm{UCS}}$, and triaxial compression strength) from experimental results. Generally, these microproperties are calibrated by a trialand-error procedure to match the mechanical parameters from experimental tests [19].

Thus, to achieve the research purpose, the microproperties represented the contact behavior should be acquired first. The predominant FJM microproperties to be calibrated are as follows: the installation gap ratio $g_{\text {ratio }}$ (when the contact interface gap $g_{s}$ is less than $g_{\text {ratio }} * \min \left(R_{1}, R_{2}\right)$; then, this contact will be assigned with the FJM contact); the flat-jointed 
contact modulus $E_{c}$; the normal-to-shear stiffness ratio $k_{n} / k_{s}$; the bonded cohesion strength $\sigma_{c}$; the tensile strength $\sigma_{t}$; the frictional coefficient $\mu$ (i.e., the residual friction angle $\left.\phi_{r}=\tan ^{-1}(\mu)\right)$; and the friction angle $\phi$ at the FJM contact interface. A detailed procedure is given in Section 3.2.2.

\subsubsection{Laboratory Tests of Intact Tuff and Microproperty} Calibration. Prior to investigating the anisotropy and scale effects on defected rockmass strength behavior, the mechanical parameters of the intact rock are first tested at a laboratory scale. Laboratory tests containing UCS tests, triaxial compression tests, and Brazilian tensile tests are conducted on intact specimens collected from the selected region at the Xiabeishan tunnel. The lithology category is tuff, a volcano chipping rock containing a little volcanic breccia, which has a weak weathering characteristic. Several cores collected from the drilling cores of the Xiabeishan tunnel are sampled and fabricated based on the stipulation of Standard for test methods of engineering rock mass (GB50266-2013); 29 standard samples of a cylindrical shape (i.e., diameter $50 \mathrm{~mm}$ and height $100 \mathrm{~mm}, \phi 50 \times 100 \mathrm{~mm}$ ) are obtained, as shown in Figure 5(a). Laboratory-scale tests are performed on these standard samples with the electrohydraulic servo triaxial rock test machine (TAW-2000; Figure 5(b)). Besides, four standard Brazilian tensile disks (i.e., diameter $50 \mathrm{~mm}$ and thickness $25 \mathrm{~mm}$ ) are also sampled for conducting the Brazilian tensile test.

Figure 5(c) shows the specimens used for conducting simulation tests in $\mathrm{PFC}^{2 \mathrm{D}}$. The specimen is the same as that in the laboratory test. A total of 10,340 particles are used in the numerical specimen for compression tests. The radius follows the uniform distribution. The inherent heterogeneity of the rock [39] induced by different mineral properties and grain sizes is ignored due to the large-scale model of the rockmass. The inherent heterogeneity of the intact rock is presented by the normal distribution with a specified deviation of contact bond strengths. The microproperties used in $\mathrm{PFC}^{2 \mathrm{D}}$ are required to match the mechanical parameters obtained from the laboratory test by conducting the simulation test. Lots of uniaxial, confining, and tensile simulation tests are conducted under different loading conditions to calibrate the required microproperties.

Figures 6(a) and 6(b) present the stress-strain curves from both the experiment and the numerical test under uniaxial and confining compression conditions (the solid lines in Figure 6). The resulting curves suggest that the average UCS of the Xiabeishan tuff is about $92.5 \mathrm{MPa}$, calculated from five UCS tests. Figure 6(a) also shows that a quick strength falling is observed in the postpeak phase with no residual strength and the tested tuff presents a typical quasibrittle trait. Figure 6(b) shows that a postpeak softening behavior is presented and the residual strength also increases with the increasing confining pressure. Figure 7(a) indicates that the failure mode under the uniaxial condition performs a typical split mode. The dominating cracks orient to the loading direction, and some dominating cracks also occur in the other fracturing paths due to the inherent heterogeneity of real rocks. Figure 7(b) shows that the failure mode transforms into a shear failure mode with the increasing confinement level.

Figure 8 shows the tensile result in the lab and numerical tests. In the experiment test, the external load is applied by a cambered loading platen. Hence, the same rigid walls are used to simulate this loading condition in the numerical test. Figure $8(\mathrm{a})$ indicates that the average Brazilian tensile strength of the Xiabeishan tuff is about 7.05 MPa. As shown in Figure 8(b), the crack initiation is slightly off-centre due to the natural microfractures and heterogeneity of real rocks, which is similar to the experiment result of discoidal samples [40, 41]. The UCS/BTS ratio of the Xiabeishan tuff is in the range of 10-18, which is a rock type with a representative quasibrittle trait. Due to the high UCS/BTS ratio and nonlinear strength behavior from laboratory tests, the FJM is instead of the PBM to simulate the intact rock matrix of the defected rockmass.

A trial-and-error procedure is conducted to calibrate the microproperties with the principles as follows: Since the change of one microproperty in FJM may simultaneously cause changes in multiple macroscopic mechanical parameters, it is a complicated iterative process until the target mechanical parameter is matched. The first step is to match the elastic modulus $E$ and Poisson's ratio $v$, which are determined by the contact modulus $E_{c}$ and the normal-toshear stiffness ratio $k_{n} / k_{s}$. By adjusting these two parameters, the intended elastic modulus $E$ and Poisson's ratio $v$ can be, respectively, matched. Then, the tensile strength $\sigma_{\mathrm{BTS}}$ from the laboratory test is matched by adjusting the bonded tensile strength $\sigma_{t}$ of the FJM $[42,43]$. The last step is to match the strength envelope curve by adjusting the bonded cohesion strength $\sigma_{c}$ and the friction angle $\phi$. The residual strength under different confinement levels is matched by adjusting the frictional coefficient $\mu$ (i.e., the residual friction angle $\phi_{r}$ ). In reality, the bonded cohesion strength $\sigma_{c}$ and friction angle $\phi$ all have a significant effect on the uniaxial and confining compression strength. Moreover, it should be noted that the relative error between numerical test and laboratory test results must be in the acceptable range.

With lots of iterative loops by the trial-and-error method, the calibrated microproperties of the FJM are listed in Table 2. The elastic modulus $E$, Poisson's ratio $v$, uniaxial compression strength $\sigma_{\mathrm{UCS}}$, Brazilian tensile strength $\sigma_{\mathrm{BTS}}$, etc. in the numerical test are compared with those from the laboratory test. Table 3 shows that the relative error of macroparameters between the numerical and laboratory tests is very small. Figure 6 indicates that the stress-strain curves from numerical simulations have a good agreement with the experimental results except that the residual strengths have a slight error on the initial curvature due to the crack closure in the laboratory specimens. Although the pore compaction stage of the stress-strain curves cannot be represented in PFC simulations, the peak strengths and postpeak behaviors can be well captured by the FJM. Figure 8(a) shows that $\sigma_{\text {BTS }}$ from the numerical test coincides well with the experimental results. Figures 7 and $8(\mathrm{~b})$ suggest that the failure modes from numerical simulations only have little difference from those from the experiment 

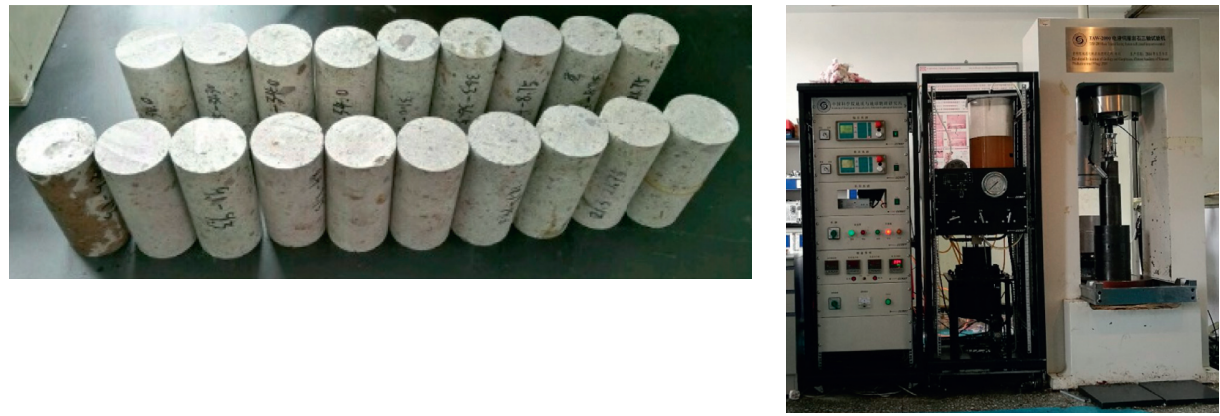

(a)

(b)

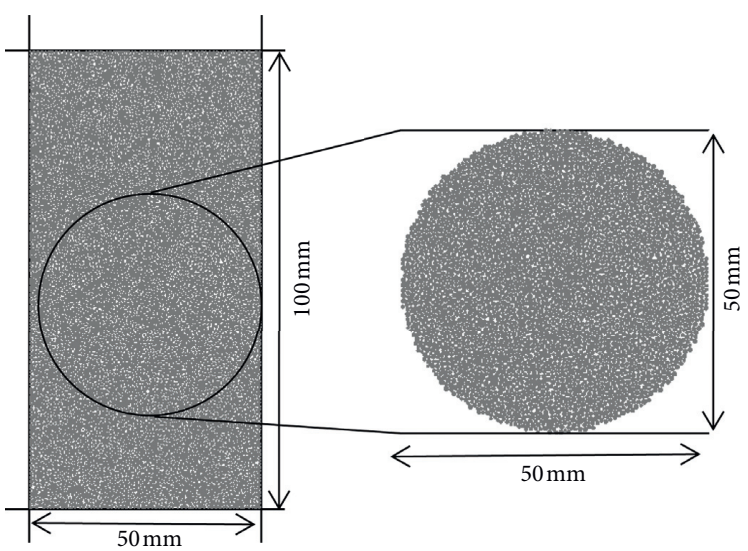

(c)

Figure 5: Intact samples cored from the Xiabeishan tunnel and numerical specimen. (a) Tested samples in the lab test. (b) Test equipment. (c) Numerical specimen generated for compression and Brazilian tensile strength tests in $\mathrm{PFC}^{2 \mathrm{D}}$.

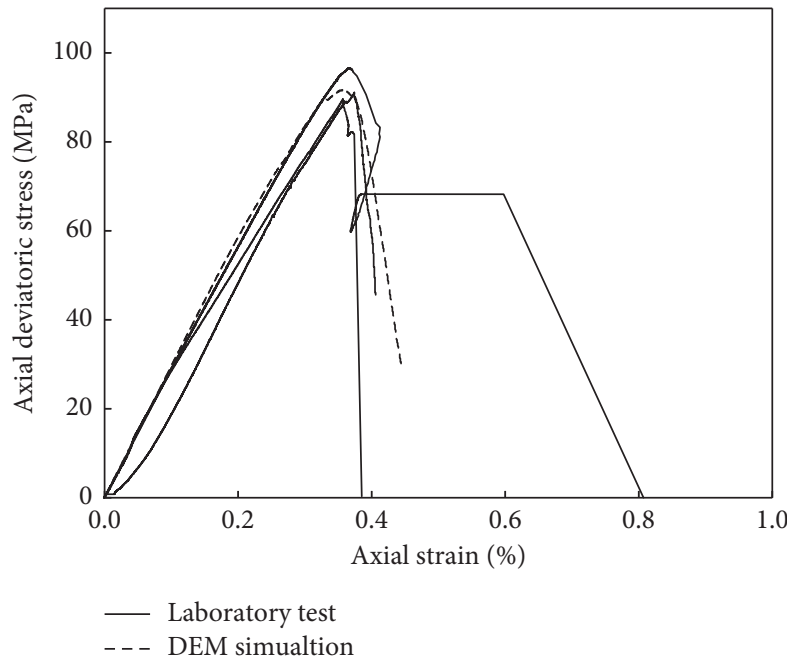

(a)

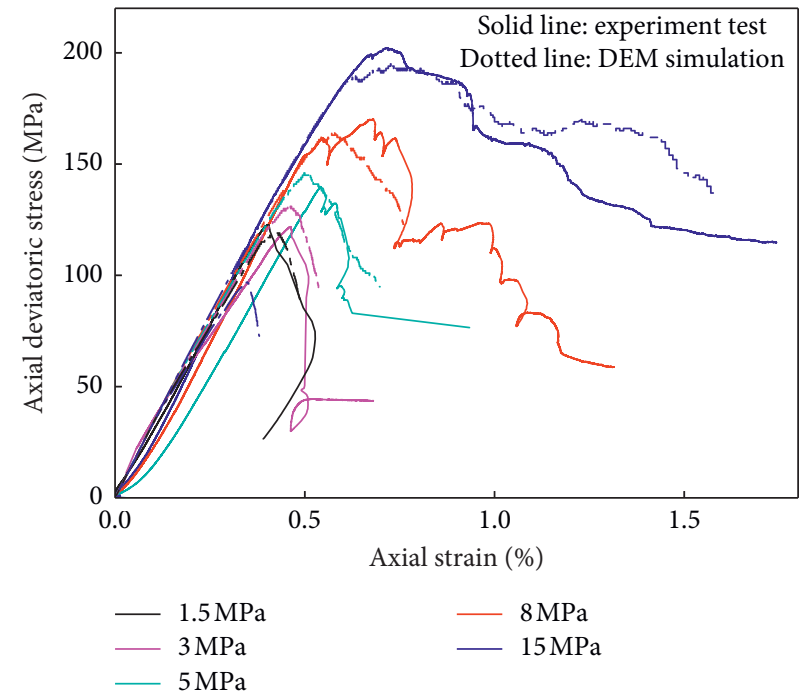

(b)

FiguRE 6: Stress-strain curves obtained from the laboratory and numerical tests. (a) Uniaxial compressive stress-strain curves. (b) Confining compressive stress-strain curves.

test under different loading conditions. Although the preexisting microdefects in real rocks cannot be adequately simulated in the PFC, the preexisting microdefects do not influence the sequential analysis of the rockmass strength behavior due to the extensive scale. The calibrated FJM properties in Table 2 provide a good simulation result of the Xiabeishan tuff at low and intermediate confinement levels (i.e., 0-15 $\mathrm{MPa}$ ). 


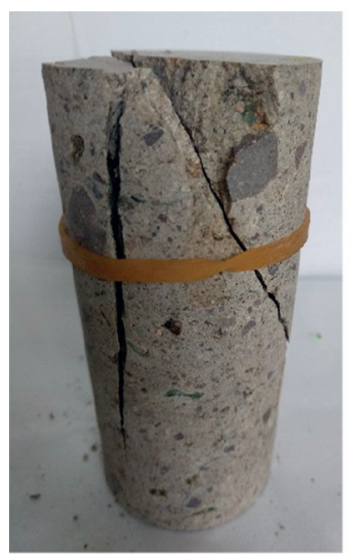

(a)

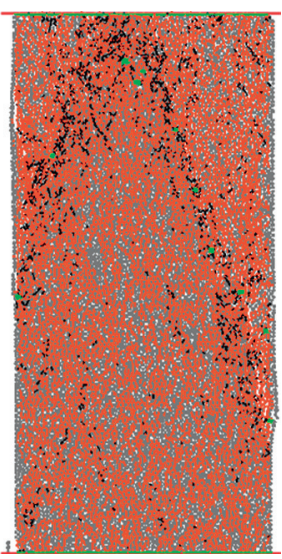

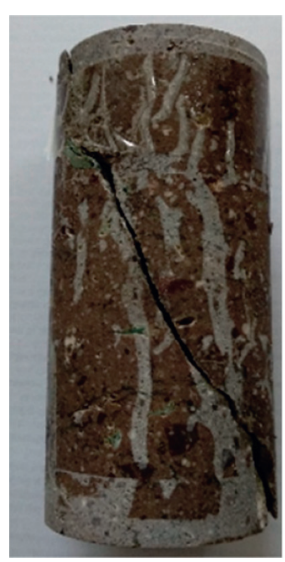

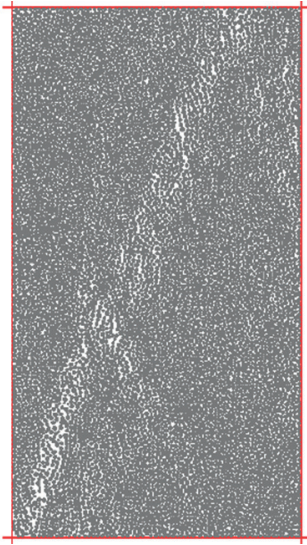

(b)

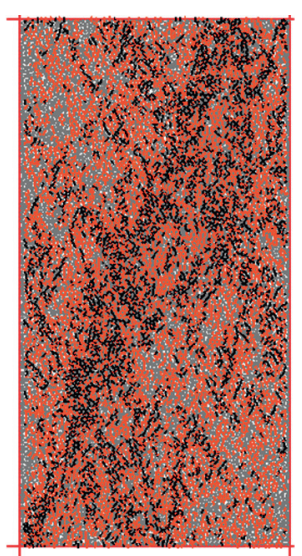

Figure 7: Failure mode. (a) Uniaxial compression test. (b) Confining compression test under the confining pressure $15 \mathrm{MPa}$ (the red line is the bonded tensile crack, and the black line is the bonded shear crack).

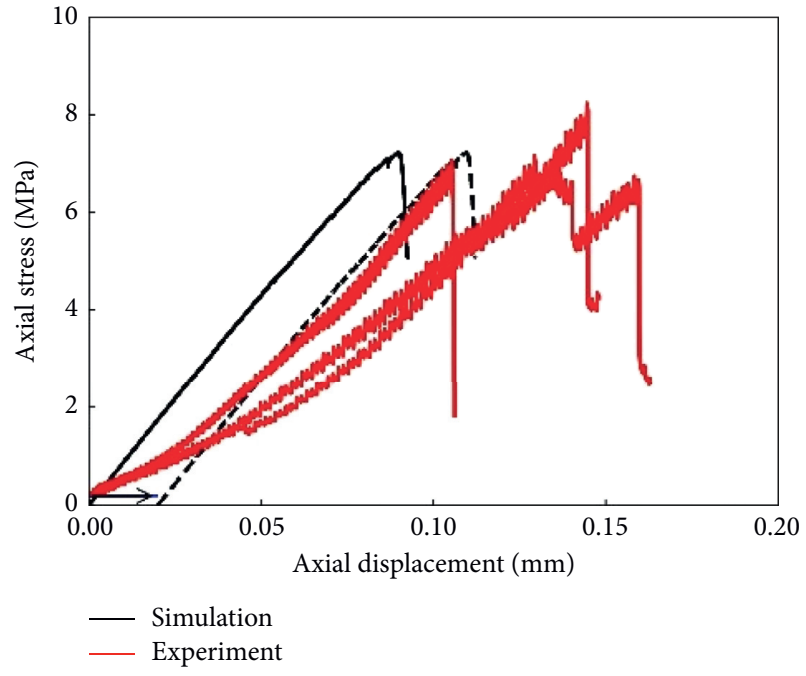

(a)
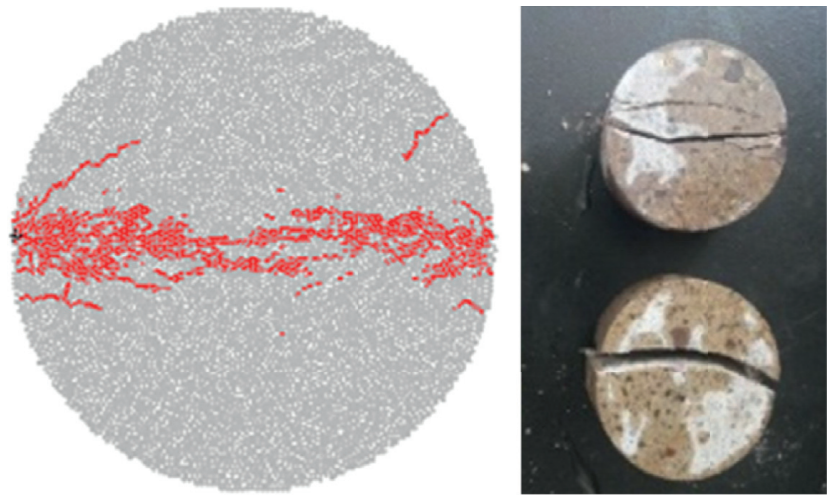

(b)

FIGURE 8: Brazilian tensile strength. (a) Stress-strain curves of the BTS tests. (b) Failure mode (right: laboratory test and left: numerical test).

TABLE 2: Microproperty calibration results of the FJM.

\begin{tabular}{lc}
\hline Microproperty & Calibration value \\
\hline Minimum radius $R_{\min }(\mathrm{mm})$ & 0.28 \\
Maximum $/$ minimum radius ratio & 1.6 \\
Density $\rho\left(\mathrm{g} / \mathrm{cm}^{3}\right)$ & 2570 \\
Installation gap ratio $g_{\text {ratio }}$ & 0.3 \\
Preexisting fracture fraction $\varphi_{\mathrm{s}}$ & 0.05 \\
Boned element fraction $\varphi_{B}$ & 0.95 \\
Number of elements $N_{r}$ & 3 \\
Contact modulus $E_{c}(\mathrm{GPa})$ & 37 \\
Stiffness ratio $k_{n} / k_{s}$ & 2.9 \\
Tensile strength $\sigma_{t}(\mathrm{MPa})$ & 11.5 \\
Bonded cohesion strength $\sigma_{c}(\mathrm{MPa})$ & 75.0 \\
Frictional coefficient $\mu$ & 0.65 \\
Friction angle $\phi\left(^{\circ}\right)$ & 20.0 \\
Linear frictional coefficient $\bar{\mu}$ & 0.5 \\
\hline
\end{tabular}

The peak strength under different confinement levels and the fitted strength envelope curve based on the Hoek-Brown strength criterion [6] are given in Figure 9. Table 3 also shows the fitted Hoek-Brown parameters. The simulation results using the PBM are also listed in Figure 9. The Hoek-Brown material constant $m_{i}$ is 20.1 fitted by the laboratory results, while the material constant $m_{i}$ is 10.7 and 18.6 based on the simulation results from the PBM and FJM, respectively. There is a slight difference between the FJM simulation results and experimental results. As expected, the FJM has a better effect in capturing the strength parameters of the Xiabeishan tuff compared with the PBM. Moreover, the inauthentic tensile strength $\sigma_{\mathrm{BTS}}$ of the PBM can also be improved by the FJM. The UCS/BTS ratio simulated by the FJM is 13.4, which is in the range of the experimental results. Therefore, the FJM can adequately represent the mechanical 
TABLE 3: Results of the laboratory tests and FJM simulations.

\begin{tabular}{lcc}
\hline Type & Laboratory results & FJM simulations \\
\hline UCS $(\mathrm{MPa})$ & $92.5(n=5)$ & 92.7 \\
Elastic modulus $(\mathrm{GPa})$ & $30.5(n=5)$ & 29.9 \\
Poisson's ratio & $0.21(n=5)$ & 0.20 \\
BTS $(\mathrm{MPa})$ & $7.05(n=4)$ & 6.92 \\
UCS/BTS ratio & $10-18$ & 13.4 \\
HB material constant $m_{i}$ & 20.1 & 19.6 \\
HB fitted $\sigma_{u}(\mathrm{MPa})$ & 96 & 100 \\
\hline
\end{tabular}

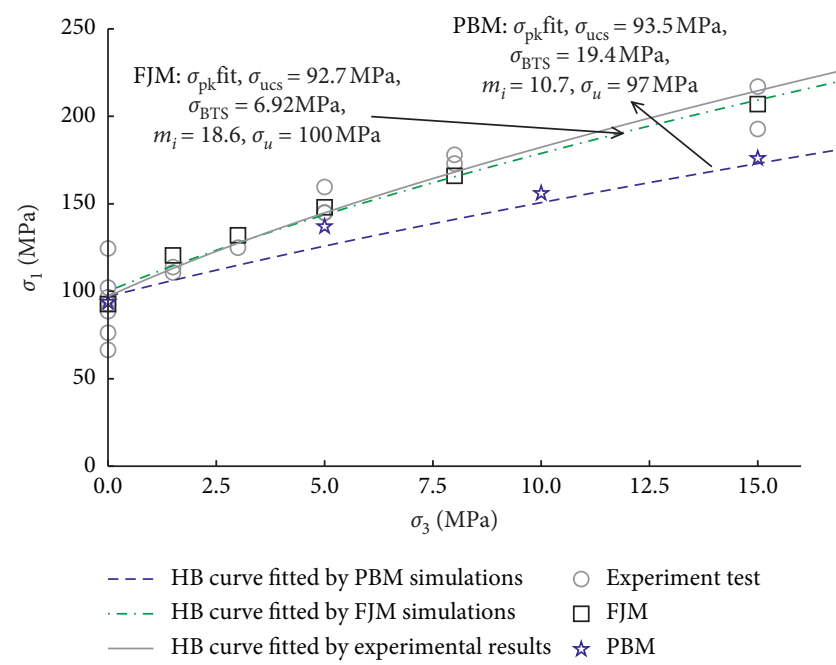

Figure 9: Peak strength of the intact tuff from laboratory and numerical tests.

behavior of the Xiabeishan tuff. The results examine that numerical analysis using the PFC is suitable for studying the defected rockmass strength behavior under the low and intermediate confinements (i.e., $0-15 \mathrm{MPa}$ ). The microproperties listed in Table 2 will be used in sequential analysis.

3.3. Defect Simulation. The mechanical behavior of discontinuous defects is influenced by several factors such as the shape, roughness, orientation, and cemented degree so that the mechanical characteristic of defects is impossible adequately in the laboratory-scale or in situ scale test. It is also difficult to consider the overall types of defects. Some assumptions should be defined in this paper due to the complex types of defects. In previous researches, the microproperties of defects are usually obtained by comparing with the experiment shear test results of the planar joint, or other types of regular joints [44], or directly assumed from the intact parts $[3,29]$. The types of defects are very complex so that it is difficult to consider the overall types of defects, and some assumptions should be defined. The defects are treated as weak cemented and closed joints conforming to the in situ condition in Figure 2 and are simulated by the smooth-jointed contact model in $\mathrm{PFC}^{2 \mathrm{D}}$. Hence, the defect is simulated by the SJM in $\mathrm{PFC}^{2 \mathrm{D}}$. The input microproperties of the SJM should be determined before conducting the numerical test. Wang et al. [32] pointed out that the strength of closed and weak cemented joints is about $0-20 \%$ of that of the intact rock matrix. Based on this assumption, the microproperties of the defects are assigned by a strength reduction factor $\alpha$ (i.e., a coefficient of the SJM strength-to-FJM strength ratio, e.g., $\alpha=\bar{\sigma}_{t} / \sigma_{t}$ or $\alpha=\bar{\sigma}_{c} / \sigma_{c}$, where $\bar{\sigma}_{t}$ is the tensile strength of the SJM, $\sigma_{t}$ is the tensile strength of the FJM, $\bar{\sigma}_{c}$ is the bonded cohesion strength of the SJM, and $\sigma_{c}$ is the bonded cohesion strength of the FJM). According to Wang et al. [32], when the strength reduction factor $\alpha$ is less than $10 \%$, the peak strengths and failure modes of the lamellated rockmass from PFC simulations have a good agreement with the laboratory results. Thus, this method is used to simulate the defects. To determine the contact stiffness of the SJM, a similar concept of the stiffness reduction factor $\beta$ is also used $[32,45]$. The stiffness reduction factor $\beta$ is the ratio of the normal or shear stiffness of the SJM to the normal or shear stiffness of the FJM. This concept is also consistent with the heterogeneity of defects. Along with the calibrated procedure of intact parts, an unbonded sawn planar fracture is conducted by the laboratory direct shear test for calibrating the stiffness reduction factor $\beta$ and the frictional coefficient $\bar{\mu}_{b}$; then, the strength reduction factor $\alpha$ can be assumed.

The numerical direct shear test is conducted to match the experimental result to calibrate the microproperties of the planar defect. The frictional coefficient $\bar{\mu}_{b}$ is determined from the direct shear test under different normal stress. Figure 10 shows the peak shear strength under different normal stress (i.e., $0.5 \mathrm{MPa}, 1.0 \mathrm{MPa}$, and $1.5 \mathrm{MPa}$ ). The microproperties of the SJM are listed in Table 4. The residual friction angle $\bar{\varphi}_{r}$ (i.e., the frictional coefficient $\bar{\mu}_{b}$ ) of the planar defect is about $29^{\circ}$, and the strength properties of the SJM (i.e., the tensile strength $\bar{\sigma}_{t}$ and bonded cohesion strength $\bar{\sigma}_{c}$ ) are determined by the strength reduction factor $\alpha$.

3.4. Procedure of Numerical Simulations. The DEM simulation analysis of the defected rockmass is designed for two types. The uniaxial compression tests are conducted on specimens with different model sizes for investigating the scale effect and REV size, and the confining compression tests are conducted under different confinement levels to investigate the confining strength. For the uniaxial tests, the top and bottom walls are applied with a loading velocity on the specimen based on the wall-based platens in the PFC, and the vertical walls of the model are kept as free surfaces. For the confining tests, the confining pressure is applied by a servo mechanism on the two vertical walls of the model using a built-in FISH language, and the external loading conditions are the same as those for the uniaxial tests.

A rational loading velocity should be selected to ensure a quasistatic equilibrium state during the calculation process. Specimens with random widths from 2 to $10 \mathrm{~m}$ are used in the uniaxial compression test. The rational loading velocity is then determined. The result shows that when the loading velocity is $0.01 \mathrm{~m} / \mathrm{s}$, the calculation result is not affected by the loading velocity. Thus, the loading velocity $0.008 \mathrm{~m} / \mathrm{s}$ is used for sequential simulations. Besides, DEM calculation conducted by the FJM is a very time-consuming process so that the calculation termination criterion should be 


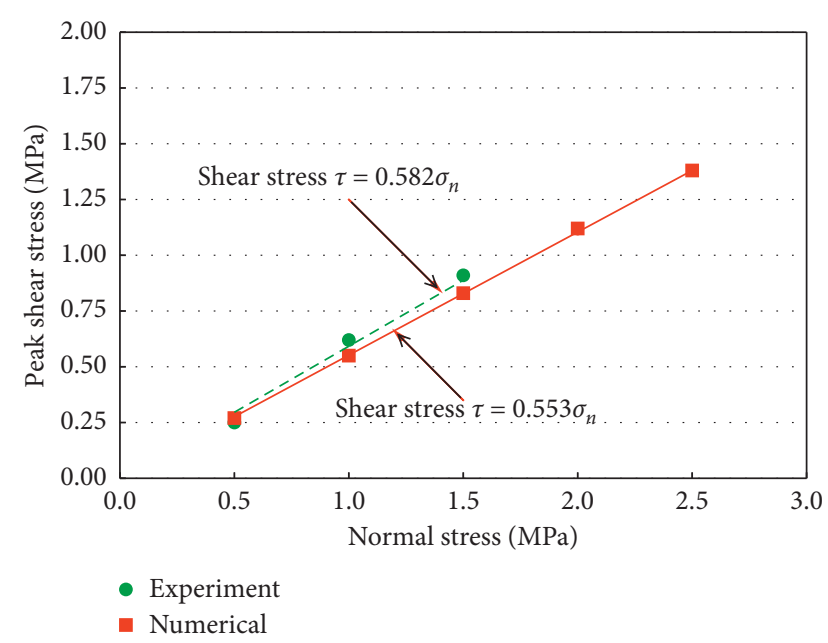

Figure 10: Peak shear strength from numerical and experiment direct shear tests on a sawn planar fracture.

TABle 4: Microproperties of the SJM.

\begin{tabular}{lc}
\hline SJM microproperty & Value \\
\hline Normal stiffness factor $\beta$ & 0.08 \\
Tensile strength $\bar{\sigma}_{t}(\mathrm{MPa})$ & 0.345 \\
Friction angle $\bar{\varphi}_{b}\left(^{\circ}\right)$ & 0 \\
Normal-to-shear stiffness ratio & 3.5 \\
Bonded cohesion strength $\bar{\sigma}_{c}(\mathrm{MPa})$ & 2.25 \\
Frictional coefficient $\bar{\mu}_{b}$ & 0.55 \\
\hline
\end{tabular}

reasonably determined. For providing more information on the rockmass strength characteristics, the calculation terminates at about $60 \%$ of the peak strength. However, if a strain-hardening or a perfect elastic-plastic behavior occurs in the stress-strain curve, the calculation is artificially terminated by the users for reducing the calculation time.

\section{Strength Characteristics of Defected Rockmass}

4.1. Anisotropy and Scale Effects on Strength Characteristics of Defected Rockmass. The rockmass strength characteristic induced by the loading direction is investigated in this section. In the uniaxial compression tests, six random samples are selected at various locations in each rotating DFN (four samples when the model width is larger than $7 \mathrm{~m}$ ) to analyze the scale effect and the REV size. The strength characteristic induced by the scale effect and loading direction is then studied through the confining compression tests.

Figures 11(a) and 11(b) show the UCS values and coefficient of variation obtained from specimens DFN120 and DFN150 (i.e., Cov, the variation from the average UCS; hollow points are the UCS values from simulations, and solid points are the calculated Covs). As pointed out by Khani et al. [46], when the Cov is less than a specific value ( $20 \%$ is chosen in their study), the REV size can be determined. The acceptable Cov value in this study is identified as
$10 \%$. Based on this concept, the average UCS and REV size for each DFN are listed in Table 5. DFN30 and DFN60 have a REV size of $4 \times 8 \mathrm{~m}$, while the REV size of DFN120 and DFN150 is $5 \times 10 \mathrm{~m}$. This result shows that the REV size is affected by the loading direction. Based on the result shown in Table 5, when the model width is larger than $5 \mathrm{~m}$, the UCS values are converged at a specific level and the Cov values are all smaller than $10 \%$. Hence, $5 \times 10 \mathrm{~m}$ can be regarded as the REV size. Besides, the strengths of specimens DFN0 and DFN90 are independent of the model size due to the structural orientation almost parallel to the critical shear stress direction. Figure 11(c) shows that the typical failure modes of specimen DFN0 with different sizes behave in a shear slip mode and the strengths are controlled by the properties of defects. Moreover, the failure modes and strengths of specimens DFN120 and DFN150 are comparable to those of specimens DFN0 and DFN90 since the shear slip failure occurs along a single defect at a model width of $2 \mathrm{~m}$ and $4 \mathrm{~m}$. When the model size reaches $6 \mathrm{~m}$, the failure combines with an axial split through the rock bridge and shear slip along with the defects.

Table 5 shows that the average UCS value of DFN30, DFN0, and DFN90 is $32.5 \mathrm{MPa}, 4.3 \mathrm{MPa}$, and $5.3 \mathrm{MPa}$, respectively. An apparent anisotropy is observed, and the strength is dependent on the loading orientation. Specimen DFN0 has the lowest strength, while specimen DFN30 has the highest strength, showing an anisotropic ratio of 7.6 (i.e., the ratio of the average UCS of DFN30 to that of DFN0). It is noted that the average trace length of defect set Set2 with a negative exponential distribution in Figure 2 is about $1.7 \mathrm{~m}$, which performs a high persistence compared with defect set Set1. When defect set Set2 orients to the critical shear stress, it plays a controlling role in the mechanical response of the rockmass. The high persistence may result in a lower strength. Specimen DFN30 indicates the highest strength, owing to the direction of defect set Set2 intersecting at a smaller angle with the loading direction. Figure 11(c) also shows that the failure modes of specimens DFN120 and DFN150 are influenced by the persistence degree of defect sets.

The result demonstrates that the rockmass strength behavior is predominantly influenced by the distribution trait of existing defects (i.e., defect orientation, persistence, and density). It should be noted that the defects may be stronger or weaker than the assigned strength values (i.e., the SJM properties used in this study: peak $\bar{\sigma}_{t}=0.345 \mathrm{MPa}$, peak $\bar{\sigma}_{c}=2.25 \mathrm{MPa}$, and residual friction angle $\bar{\varphi}_{r}=29^{\circ}$ ) of other rockmass types, which may result in a lower or higher strength of other defected rockmass types. For the DEM simulation work in this paper, the rockmass strength is dependent on the specimen size and cannot be directly estimated based on the small standard specimen scale from the laboratory test, and the REV size is influenced by the defect orientation and confinement levels. For the defect orientation almost parallel to the critical shear stress orientation, the REV size is influenced by the defect lengths and the strength cannot be directly determined from the small sample strength. The REV size and strength of the defected rock on a small scale can be determined by conducting scale 


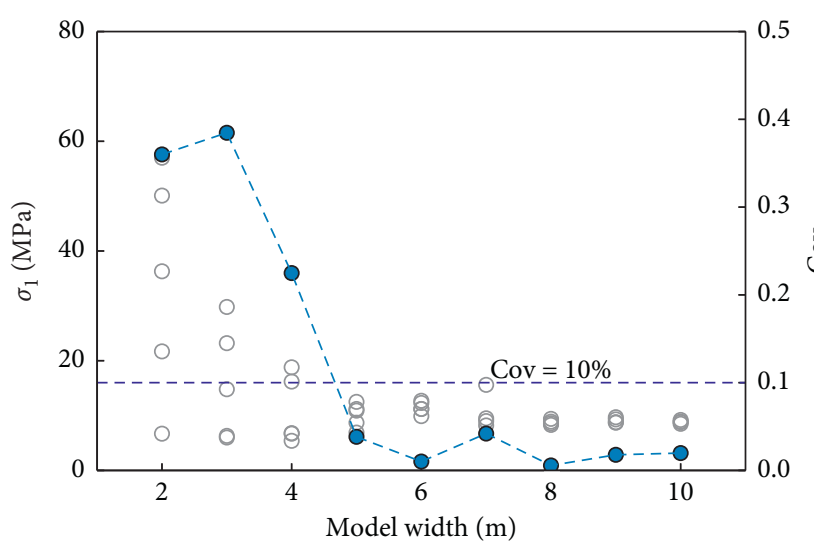

(a)

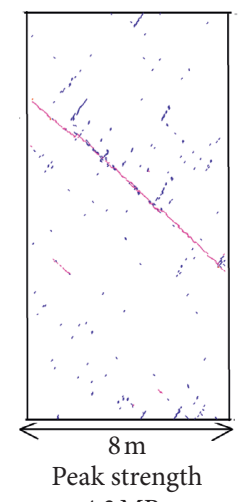

$4.3 \mathrm{MPa}$

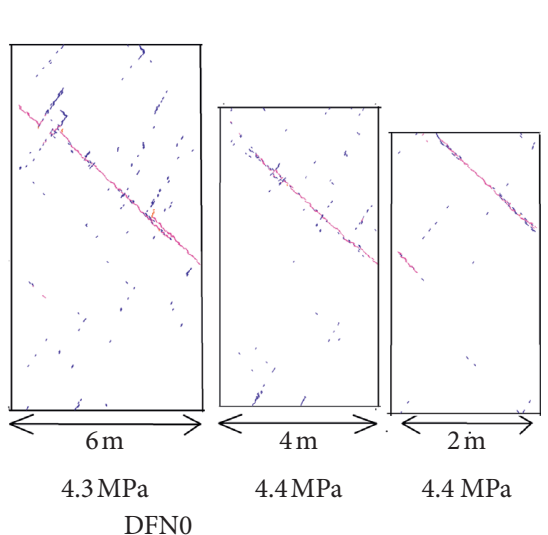

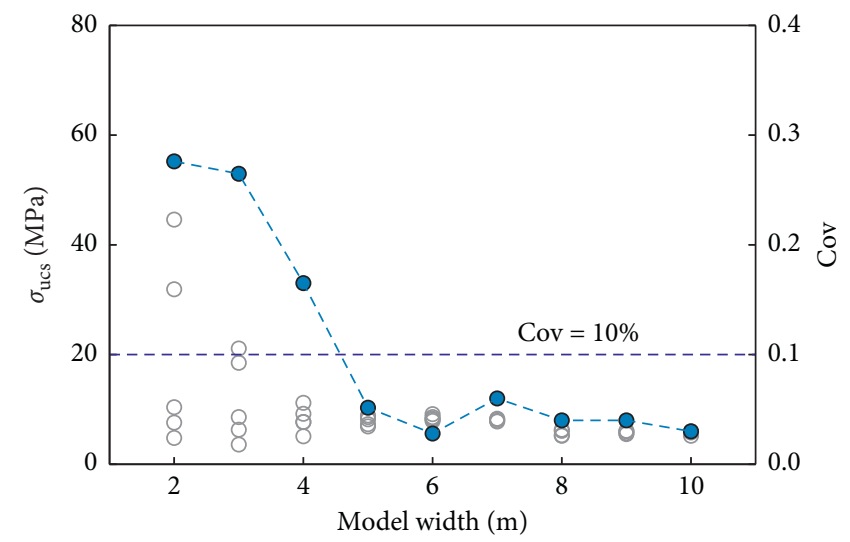

(b)
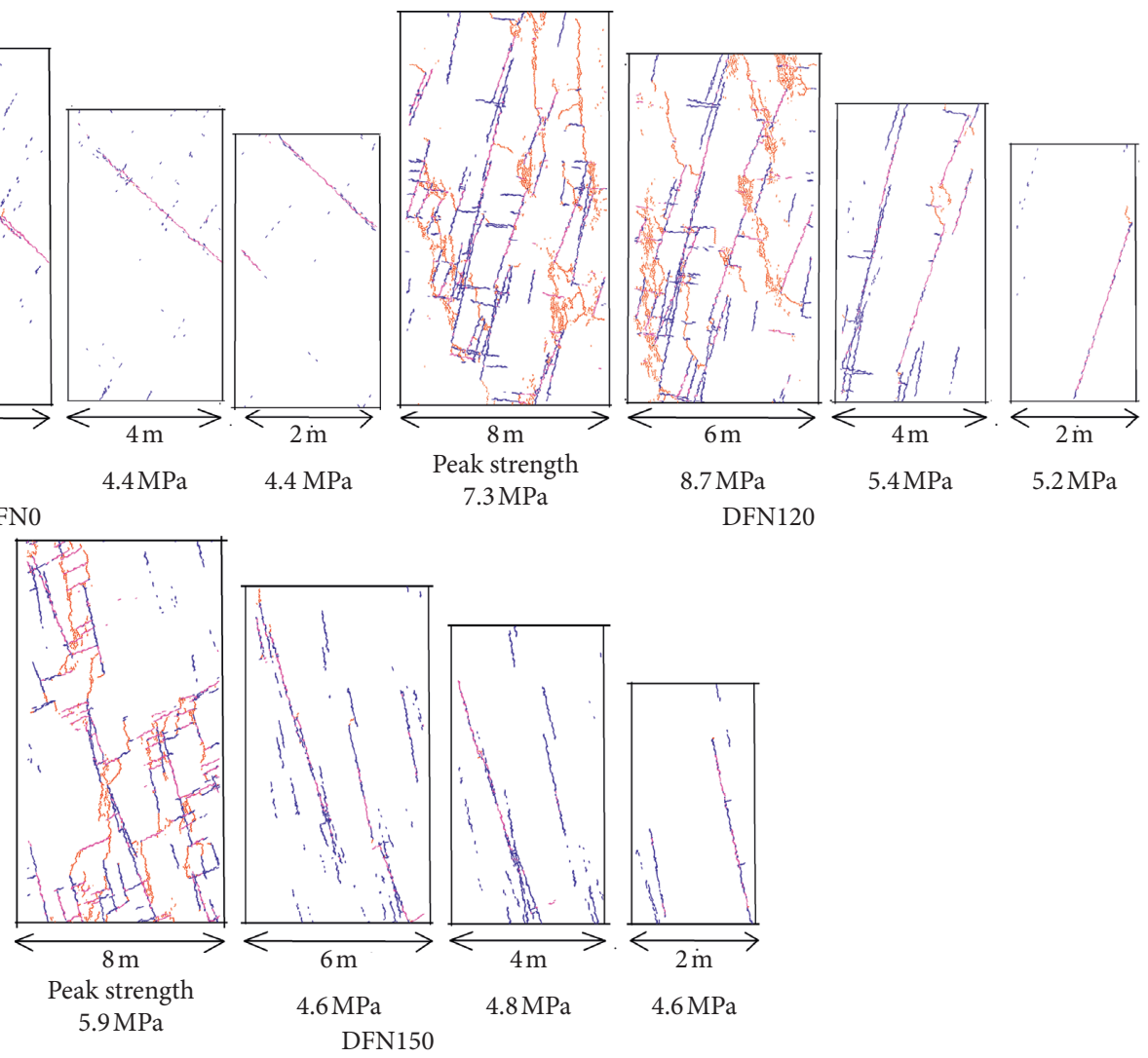

(c)

FIGURE 11: Effect of the model size on the UCS values of specimens (a) DFN150 and (b) DFN120. (c) Influence of the model size on the failure mode. Note that the specimens are generated based on the centre of the DFN model and the scale for each model is not the same for convenience.

TABLE 5: Results of the UCS and REV size under different loading directions.

\begin{tabular}{lccc}
\hline DFN & Average UCS value $(\mathrm{MPa})$ & REV size $(\mathrm{m})$ & Cov $(\%)$ \\
\hline DFN0 & 4.3 & - & - \\
DFN90 & 5.3 & - & 5 \\
DFN30 & 32.5 & 4 & 1.6 \\
DFN60 & 12.6 & 5 & 5.2 \\
DFN120 & 7.2 & 5 & 3.5 \\
DFN150 & 8.9 & 4.2 \\
\hline
\end{tabular}


effect tests [47]. However, the large-scale in situ tests of the rockmass are difficult to conduct, and they are usually expensive to control boundary conditions. Therefore, when the properties of intact parts and defects in the rockmass are calibrated, numerical simulations can serve as an alternative to estimate the rockmass mechanical behavior. The REV size can be regarded as $5 \times 10 \mathrm{~m}$, which is used to investigate the stress-strain curves and failures modes of the rockmass under the confining conditions.

Based on the results of uniaxial tests, DFN30 specimens with different widths (i.e., $2 \mathrm{~m}, 3 \mathrm{~m}, 4 \mathrm{~m}, 5 \mathrm{~m}, 8 \mathrm{~m}$, and $10 \mathrm{~m}$ ) are conducted to study the confining strength characteristic. The confining pressure is $1.5 \mathrm{MPa}, 3 \mathrm{MPa}, 5 \mathrm{MPa}, 8 \mathrm{MPa}$, $12 \mathrm{MPa}$, and $15 \mathrm{MPa}$, respectively. The peak strengths of the defected rockmass with different sizes under different confinement levels are shown in Figure 12.

Figure 12 shows that the confinement level also affects the REV size. Because of the confining pressure, the rockmass strength is converged at the model width of $4 \mathrm{~m}$, which is smaller than the REV size that resulted from the uniaxial tests. When the confining pressure is less than $3 \mathrm{MPa}$, the peak strengths of specimens with model widths $2 \mathrm{~m}$ and $3 \mathrm{~m}$ are higher than those of specimens with widths $4 \mathrm{~m}$ and $8 \mathrm{~m}$. As the confining pressure increases, the peak strength of the specimen with model width $4 \mathrm{~m}$ is close to that of the specimen with model width $5 \mathrm{~m}$.

4.2. Stress-Strain Curve Analysis of Defected Rockmass. In this section, the specimen of size $5 \times 10 \mathrm{~m}$ with a height-towidth ratio of 2.0 is conducted by a series of uniaxial and confining compression tests under different loading directions. The stress-strain curve, peak strength, and failure mode of the rockmass are analyzed. As shown in Figure 13, Hoek et al. [6] classified three types of stress-strain curves for the rockmass with different qualities. According to this classification, the type of the stress-strain curve is qualitatively discussed by considering the effect of the loading direction and confinement level.

Figure 14 shows the stress-strain curves and failure modes of specimens DFN0 and DFN150 under uniaxial compression conditions. As shown in Figure 14(a), the loading direction strongly impacts the UCS of the defected rockmass. Specimen DFN30 shows the highest UCS (i.e., $35 \mathrm{MPa}$ ), while the UCS values of other specimens are in the range of 4-9 MPa. Similarly, the peak strain of specimen DFN30 is much larger than that of the other specimens. Moreover, the postpeak behaviors of specimens DFN60 and DFN120 express more ductility than those of the other specimens. The simulation result shows that the rockmass strength at the REV size is not only stress-dependent but also loading direction-dependent. The distributed nature of the DFN is the main reason that caused the strength anisotropy, and the direction and persistence of defects are also the main controlling factors of the rockmass strength. Note that the average trace length of defect set Set2 is larger than that of defect set Set1, showing a larger persistence (see Figure 2). Figure 14(b) shows that when defect set Set2 orients parallel to the critical shear stress direction, defect set Set2 with a low

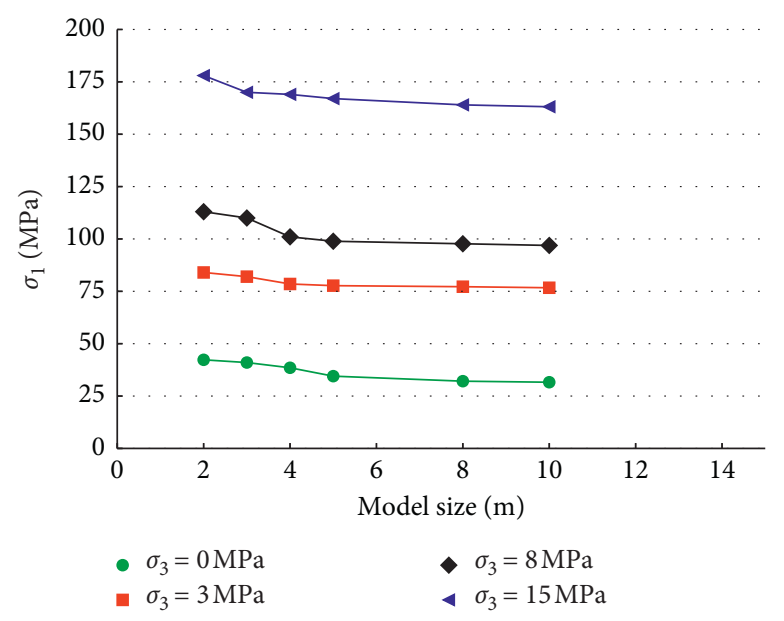

FIGURE 12: Effect of the confining pressure on peak strengths of specimen DFN30.

persistence becomes the "control defect set." The control set of the defected rockmass changes with the loading directions. Specimens DFN0, DFN90, and DFN150 show an obvious shear slip along defect set Set2. The split failure mode appears in specimen DFN30 due to the orientation of defect set Set 1 almost parallel to the loading direction so that specimen DFN30 presents a relatively higher strength. While the mixture failure mode appears in specimens DFN60 and DFN120, the strength behaviors containing crack distribution, propagation, and merging are controlled by the interaction between defects and intact parts in these specimens.

Figure 15 lists the peak strengths when the specimen size is $5 \times 10 \mathrm{~m}$ under various confinement levels and different loading directions. Specimen DFN30 has the highest strength, while specimens DFN0 and DFN90 have a relatively low strength at the same confinement level. The resulting nonlinear strength envelope curves of specimens DFN0, DFN30, DFN120, and DFN150 suggest a bilinear failure envelope, which is similar to the experimental results of saw-blade fractures reported by Patton [48]. The peak strengths of these specimens have an increasing trend with the increasing confinement level when the confining pressure is lower than $3 \mathrm{MPa}$. According to the slope of the strength envelope, a higher equivalent friction angle occurs under a low confinement level (i.e., $<3 \mathrm{MPa}$, the red frame in Figure 15). Under this condition, the equivalent friction angle of the rockmass is higher than that of the intact rock and decreases with the increasing confinement level. This simulation result is similar to the research result of interlocked blocky rockmass strength reported by Alshkane et al. [49]. However, the strength results of specimens DFN0 and DFN90 (see Figures 15 and 12(a)) are in a unique linear strength relationship and are consistent with the Mohr-Coulomb strength criterion. The strength properties of defects in specimens DFN0 and DFN90 control the defected rockmass strength. When defect set Set2 with a small persistence degree becomes the "controlling defect set" (i.e., defect direction almost parallel to the critical shear 


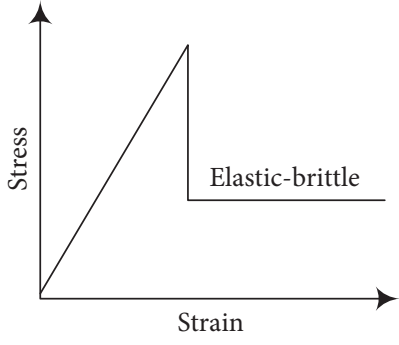

(a)

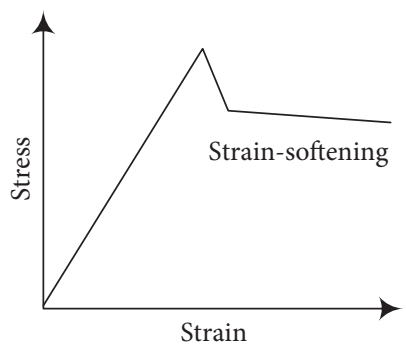

(b)

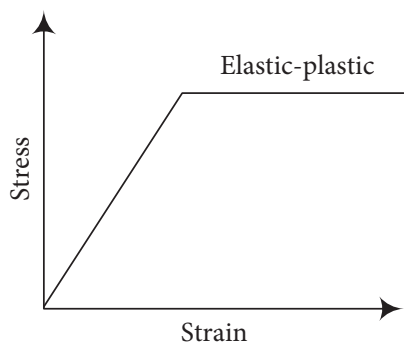

(c)

FIGURE 13: Expected stress-strain behavior of the rockmass with different qualities (Hoek et al. [6]).
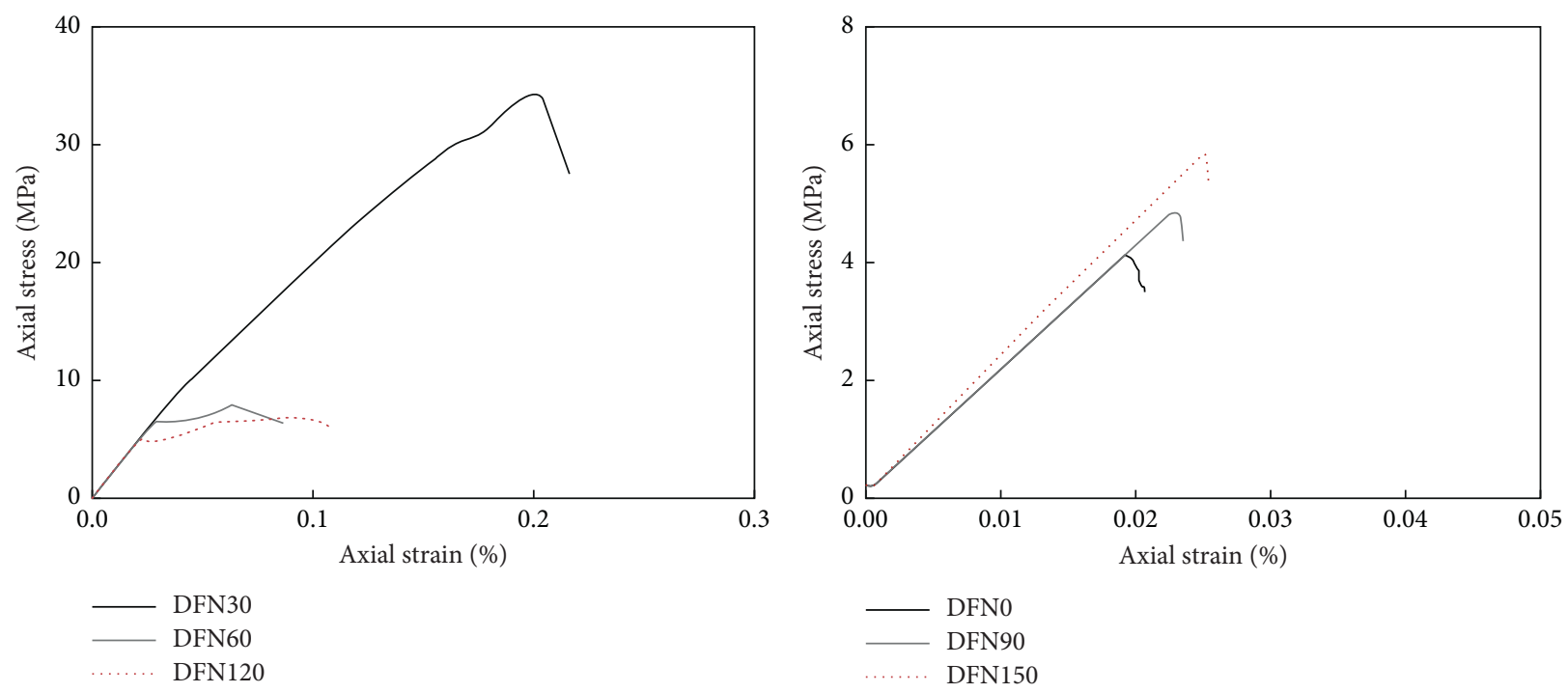

(a)
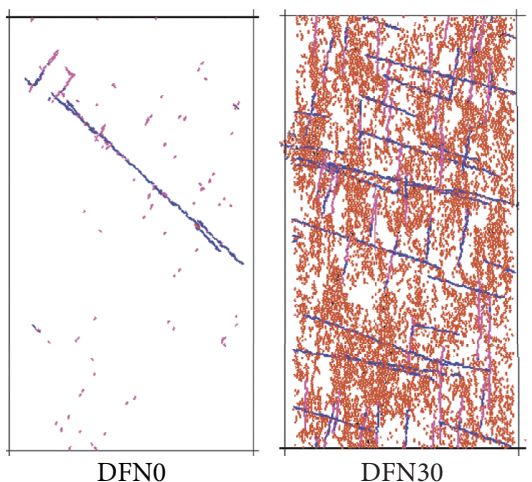

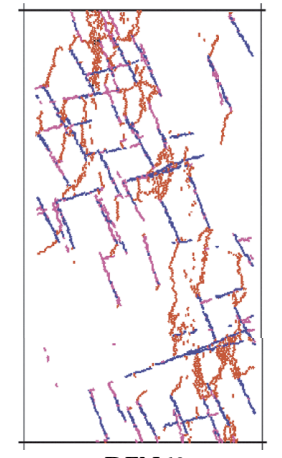

DFN60

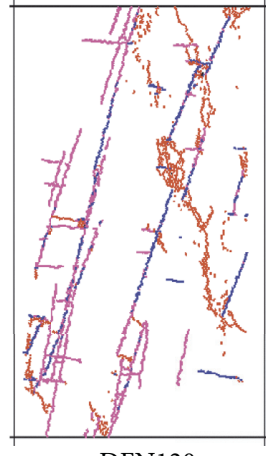

DFN120

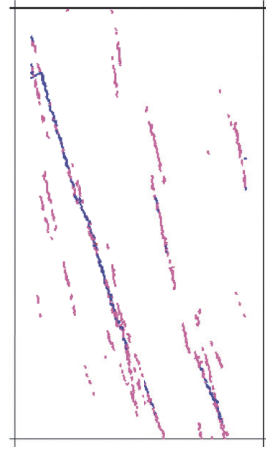

DFN150

(b)

FIGURE 14: Uniaxial compression results for the specimen of size $5 \times 10 \mathrm{~m}$ under different loading directions. (a) Stress-strain curves under different loading directions. Note that the blue line is the SJM bond tensile crack, the magenta line is the SJM bond shear crack, the red line is the FJM bond tensile crack, the black line is the FJM bond shear crack, and the gray line is the model boundary. (b) Failure modes under different loading directions.

stress direction), the strength behavior of the defected rockmass is influenced by the persistence degree of the controlling defect set. In brief, the simulation result indicates that the persistence of defects plays a significant role in the confining strength and failure modes.

Figure 16 presents the stress-strain curves at various confinement levels and the failure modes under the confining pressure $1.5 \mathrm{MPa}$ and $15 \mathrm{MPa}$. According to the simulation results, the stress-strain curves and failure modes are significantly influenced by the loading direction and can be identified as different types.

As can be seen in Figures 16(a) and 16(d), the failure modes can be identified based on the microcrack distribution. In specimens DFN0 and DFN90, the dip angles of 


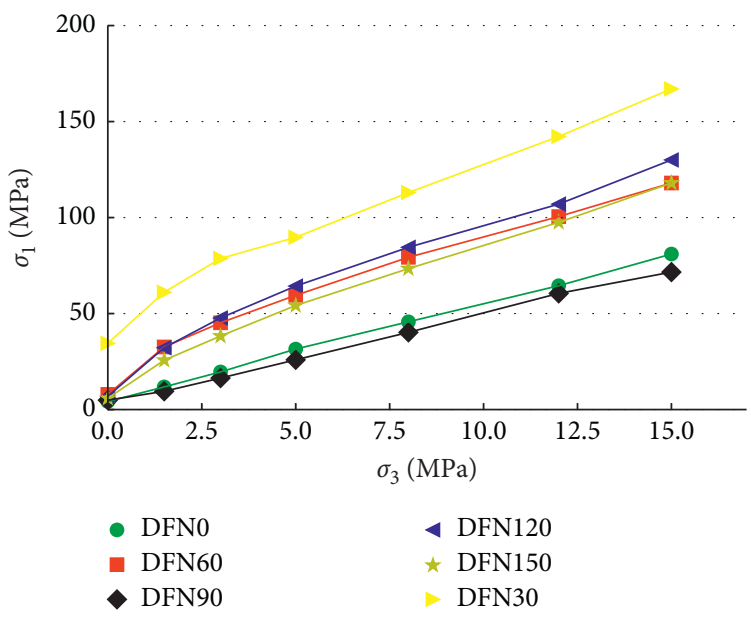

Figure 15: Peak strength envelope curves when the specimen size is $5 \times 10 \mathrm{~m}$.
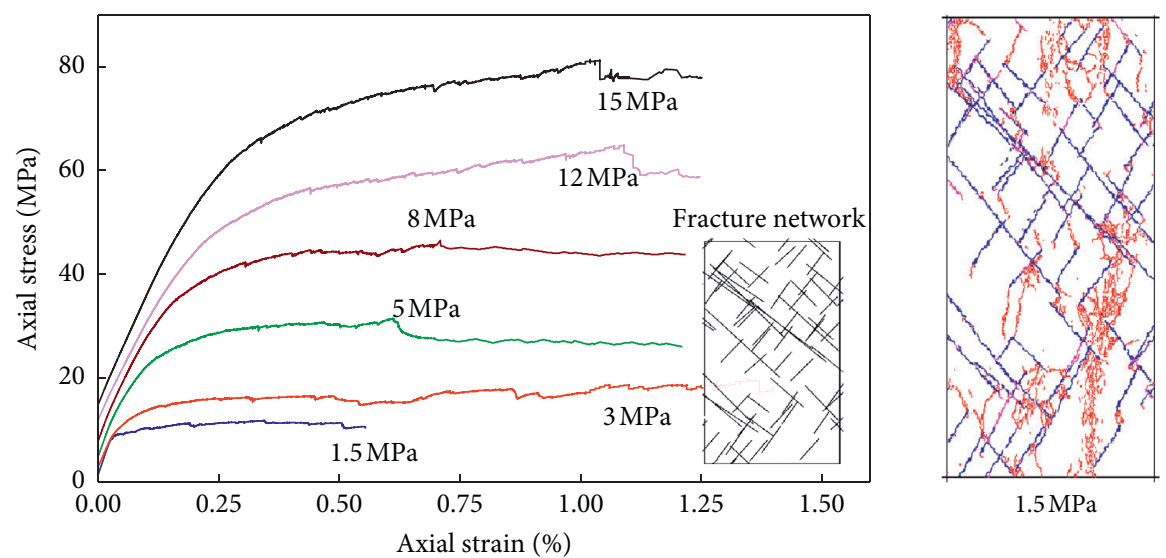

(a)

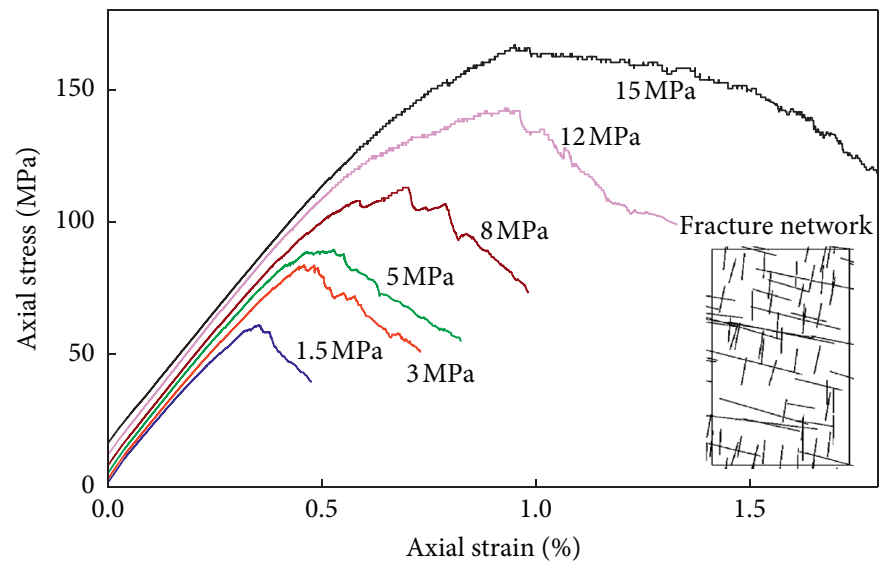

(b)
$1.5 \mathrm{MPa}$

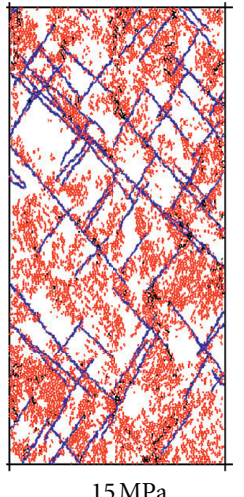

$15 \mathrm{MPa}$

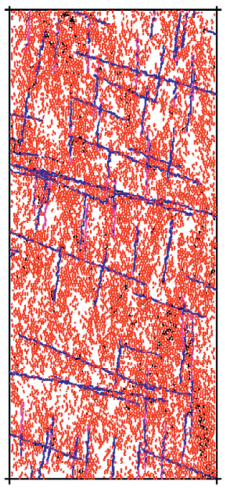

$1.5 \mathrm{MPa}$

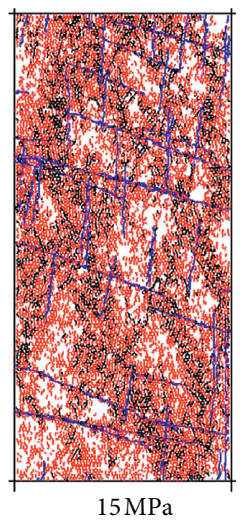

FIgURE 16: Continued. 


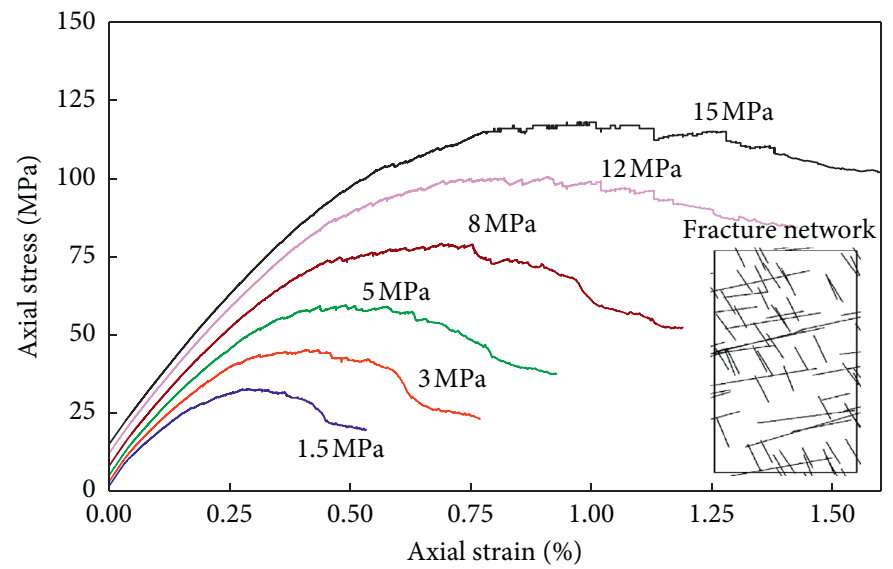

(c)

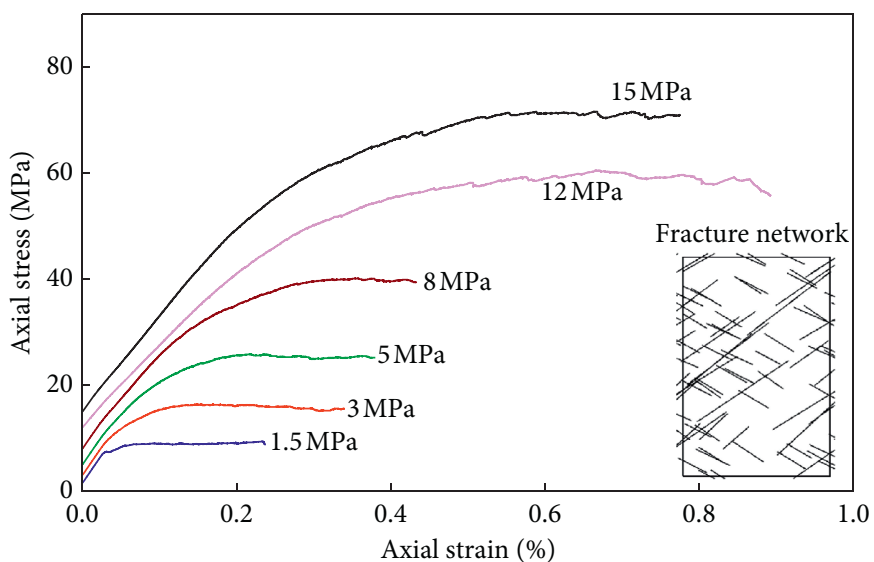

(d)

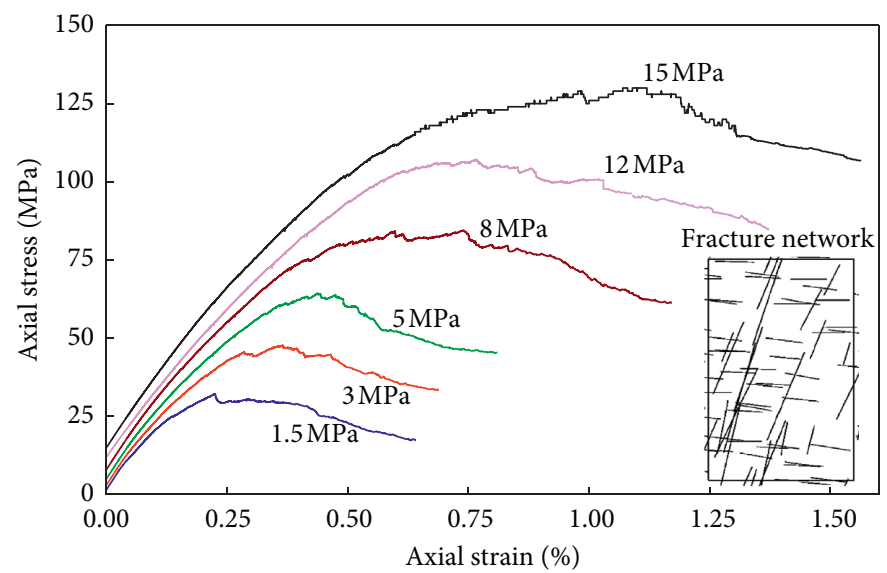

(e)

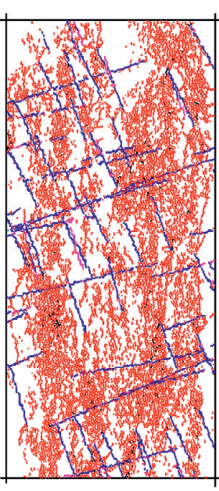

$1.5 \mathrm{MPa}$

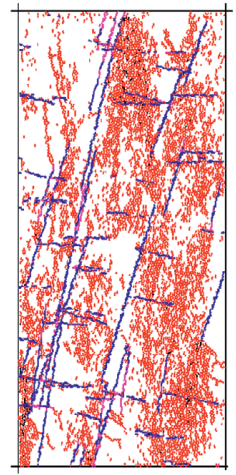

$1.5 \mathrm{MPa}$

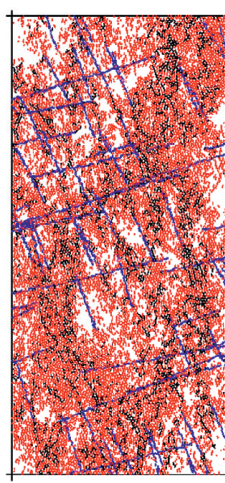

$15 \mathrm{MPa}$

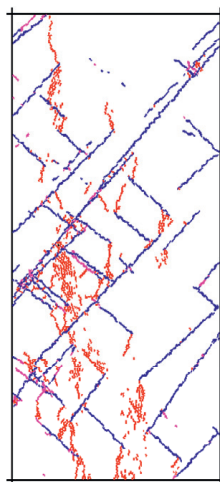

$1.5 \mathrm{MPa}$

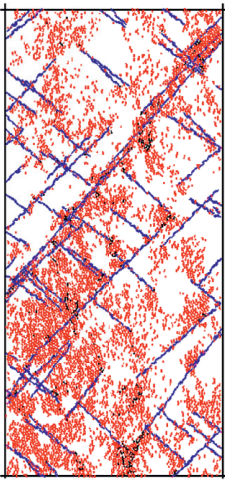

$15 \mathrm{MPa}$

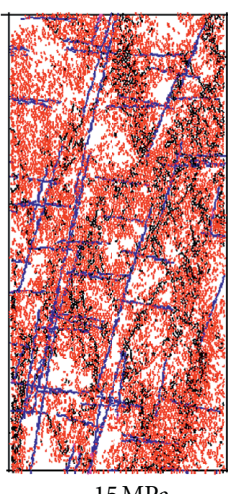

$15 \mathrm{MPa}$

Figure 16: Continued. 


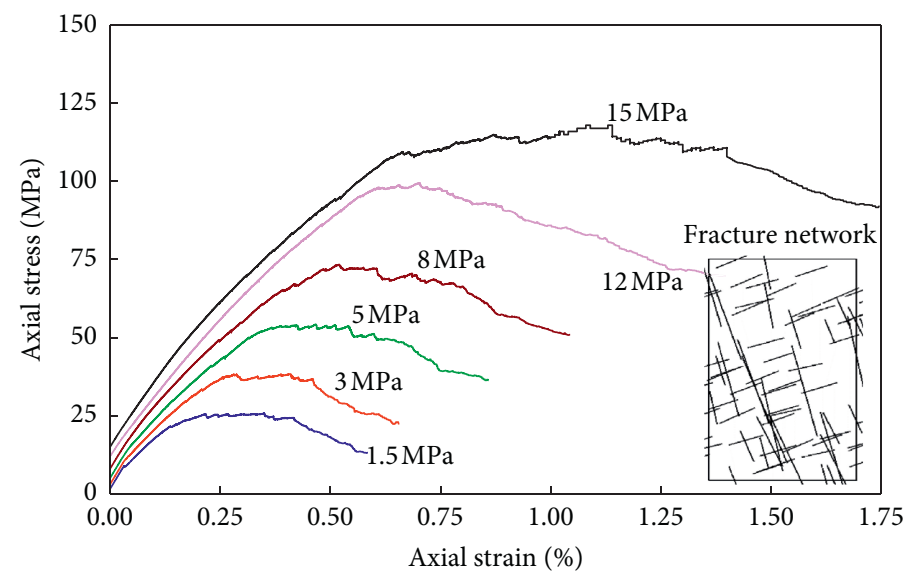

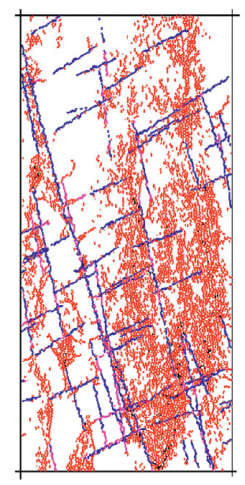

$1.5 \mathrm{MPa}$

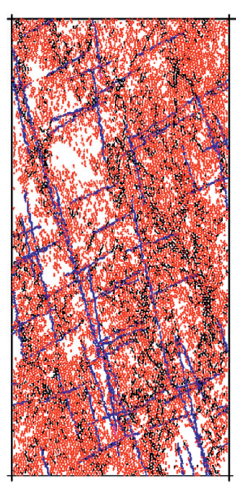

$15 \mathrm{MPa}$

(f)

FIGURE 16: Stress-strain curves and failure modes of the specimen of size $5 \times 10 \mathrm{~m}$ under different confining pressures. (a) DFN0. (b) DFN30. (c) DFN60. (d) DFN90. (e) DFN120. (f) DFN150. Note that the blue line is the SJM tensile crack, the magenta line is the SJM shear crack, the red line is the FJM tensile crack, and the black line is the FJM shear crack.

defects are almost parallel to or intersect at a small angle with the critical shear stress direction. The strengths of these specimens are lower than those of the other specimens under the same confinement level. Due to the inclined defects with a dip angle of about 45 or 135 in these specimens, a similar linear elastic type is presented in the stress-strain curves until the shear failure of defects occurs. When the confining pressure is $1.5 \mathrm{MPa}$, the stress-strain curve occurs in a linear elastic mode until the axial strain reaches $0.04 \%$. Since then, numerous tensile cracks initiate and propagate through the tips of the defects due to the suppression of the shear slip behavior of defects. As the axial strain increases continuously, the strength increment becomes very small due to the rotation of these disaggregated tire rock blocks. A composite combined with the rotation of rock blocks and slipping mode of defects occurs finally. As the confinement level increases to a high level (e.g., $15 \mathrm{MPa}$ ), a similar linear elastic mode is presented until the axial strain reaches a specific level. Then, the strength increment becomes very slow until the axial stress reaches the peak. In the peak stress stage, the shear slip behaviors of defects are restrained, and tensile cracks begin to accumulate along with the tips of defects. The shear cracks also generate in these regions when the axial stress exceeds the peak. Finally, the specimen presents in several split bands.

Figure 16(b) presents the stress-strain curves and failure modes of specimen DFN30 under different confining conditions. In specimen DFN30, the dip angles of the two defect sets are either subhorizontal or subvertical with the loading direction, i.e., $10-15$ and $75-80$. Although the residual strength cannot be fully represented due to the tedious calculation time, the stress-strain curves of specimen DFN30 under these confining conditions all have a strain-softening behavior. The stress-strain curve occurs in the linear elastic type until the axial stress reaches peak, and then the axial stress decreases quickly at the postpeak stage. With the increasing external applied loading stress, most defects fail in shear fracturing, and wing cracks at the tips of defects also occur until the axial stress reaches the peak. The combination of shear slipping of defects and tensile fracturing at the tips of defects results in the decrease of the slope. The axial stress gradually decreases as the disintegration of the intact rock bridges, and then the stress-strain curve has a strain-softening behavior in the postpeak stage. The strainsoftening tendency (i.e., the postpeak modulus) also changes with the confinement level. The failure mode under the confining pressure $1.5 \mathrm{MPa}$ shows a split mode, which is similar to the failure mode under the uniaxial condition (also see Figure 14(b)). As the confining pressure increases, the failure mode under the confining pressure $15 \mathrm{MPa}$ (see Figure 16(b)) transforms from the spilt failure mode to the multiple shear failure mode. The interaction between defects and rock bridges aggravates with the increasing confinement level. Numerous shear crackings generate in the rock bridges at the postpeak stage, and the initiation and propagation of tensile crackings also occur in the rock bridges. The failure mode of specimen DFN30 is similar to that of the intact rocks.

Figures 16(c), 16(e), and 16(f) present the stress-strain curves and failure modes of specimens DFN60, DFN120, and DFN150. In these specimens, the dip angles of two defect sets intersect at a small angle (about 20-35) with the critical shear stress direction, and the shear slip of defects is more difficult than that in specimens DFN0 and DFN90. The stress-strain curves occur in a similar postpeak softening type with specimen DFN30 under the confining conditions. However, Figures 16(c), 16(e), and 16(f) show that the strain-softening level in these specimens is lower than that in specimen DFN30 under the same confining pressure. The residual strengths of specimens DFN60, DFN120, and DFN150 are also higher than that of specimen DFN30 under the same confining condition. The resulting failure modes suggest that the defect length controls the material response in the loading process. When the confining pressure is 1.5 $\mathrm{MPa}$, the stress-strain curve presents a linear elastic relation until the axial strain reaches about $0.1 \%$; then, the 
TABle 6: Equivalent Mohr-Coulomb strength parameters under different loading directions.

\begin{tabular}{lcccccc}
\hline Loading direction & 0 & 30 & 60 & 90 & 120 & 150 \\
\hline Macroscopic cohesion $c(\mathrm{MPa})$ & 1.72 & 24.61 & 5.72 & 1.91 & 5.35 & 4.13 \\
Internal friction angle $\varphi\left({ }^{\circ}\right)$ & 39.3 & 54.9 & 55.4 & 37.9 & 57.1 & 54.3 \\
\hline
\end{tabular}

slope gradually decreases until the axial stress reaches the peak due to the local shear failure of some defects and tensile fracturing of rock parts at the tips of defects. As there is a continuous increase of axial strain in the postpeak stage, the intensive interaction between defects and intact parts results in a decreasing postpeak modulus. The intact bridges begin to disintegrate in this process. The axial stress gradually converges at a specific residual strength which increases with the increasing confinement level. The final failure mode is a mixed mode consisting of the rotation of rock blocks and the shear failure along with the defects. As the confining pressure reaches $15 \mathrm{MPa}$, lots of tensile crackings accumulate at the tips of defects until the axial stress reaches the peak and then combines with the tensile crackings toward adjacent defects at the peak and postpeak stages. Some intact parts in the intersection regions among different defect sets also occur in the shear failure type, which finally results in the multiple shear failure mode in the specimen.

\subsection{Equivalent Strength Parameters of Defected Rockmass.} The Mohr-Coulomb strength criterion is the most frequently used failure criterion in practical engineering and analysis software. The peak strength of the rockmass from simulations can be transformed into the equivalent Mohr-Coulomb strength parameters. The Mohr-Coulomb strength criterion is expressed as [50]

$$
\sigma_{1}=\frac{2 c \cos \varphi}{1-\sin \varphi}+\frac{1+\sin \varphi}{1-\sin \varphi} \sigma_{3}
$$

where $c$ is the macroscopic cohesion and $\varphi$ is the internal friction angle.

The macroscopic cohesion $c$ and internal friction angle $\varphi$ can be calculated by the slope $a$ and the $y$-intercept $b$ of the regression line by using the linear regression method. The macroscopic cohesion $c$ and the internal friction angle $\varphi$ are expressed as follows [50]:

$$
\begin{aligned}
& \varphi=\arcsin \left(\frac{a-1}{a+1}\right), \\
& c=\frac{b(1-\sin \varphi)}{2 \cos \varphi} .
\end{aligned}
$$

The equivalent Mohr-Coulomb strength parameters of the internal friction angle $\varphi$ and macroscopic cohesion $c$ determined from the linear regression method are presented in Table 6. Note that the fitted confining pressure is selected from 0 to $5 \mathrm{MPa}$, which is in the range of the stress level of practical engineering.

Based on the fitted data in Table 6, the equivalent Mohr-Coulomb strength parameters depend on the defect or loading direction. The loading direction at $30^{\circ}$ shows the highest macroscopic cohesion $c$, and this parameter depends on the dip angles of the defected rockmass. When the loading direction is $0^{\circ}$ and $90^{\circ}$, the internal friction angle $\varphi$ is $39.3^{\circ}$ and $37.9^{\circ}$, respectively. Specimen DFN0 shows the lowest equivalent Mohr-Coulomb strength parameters due to the defect direction almost parallel to the critical shear stress direction. It can be concluded that the macroscopic cohesion $c$ is more sensitive to the effect of the loading direction than the internal friction angle $\varphi$.

\section{Conclusions}

In this paper, the anisotropy and scale effects on the strength characteristics of the defected rockmass are systematically investigated using a synthetic rockmass (SRM) approach in $\mathrm{PFC}^{2 \mathrm{D}}$ based on the engineering background of a high-speed railway tunnel project in China. A lot of SRM specimens are generated by inserting the DFNs into intact rock models. The newly developed flat-jointed model (FJM) is used instead of the original PBM in the SRM model. After calibrating the microproperties of the defects and intact rock matrix (i.e., microproperties of the flat-jointed model and the smoothjointed model), numerous uniaxial and confining simulation tests are conducted on specimens generated from the rotated DFNs. The presented results will help the selection of rockmass mechanical parameters in engineering applications. The main conclusions are summarized as follows:

(1) The mechanical parameters of the intact rock (e.g., UCS, BTS, and confining strength) from experimental tests are matched by the FJM. The material response of the intact rock tuff is carefully considered in the DEM, and particularly the tensile strength is always overestimated and neglected in previous researches.

(2) The strength behavior of the defected rockmass is significantly influenced by the persistence degree of defect sets within. The DEM result shows that the peak strength of the considered rockmass presents an anisotropic trait and scale effect due to the existing defects. The equivalent Mohr-Coulomb strength parameters strongly depend on the loading direction, and the macroscopic cohesion $c$ is more sensitive to the loading direction than the internal friction angle $\varphi$.

(3) The REV size of the intended research region can be regarded as $5 \times 10 \mathrm{~m}$ under the uniaxial condition. The defect direction and confinement level have a significant influence on the scale effect of the defected rockmass.

(4) According to the simulation results of confining tests, the stress-strain curves and failure modes of specimens with REV size occur in different types: for specimens DFN0 and DFN90, a perfect elasticplastic mode occurs due to the dip angles of defects 
oriented almost parallel to the critical shear stress and a composite failure mode also occurs in combination with the shear failure of defects and the rotation of rock blocks; a postpeak softening behavior with different strain-softening extent occurs in the other specimens, the residual strength also gradually increases with the increasing confinement level, and the failure mode transforms from a combination of the shear failure of defects and rotation of rock blocks to disintegrating of rock blocks as the confinement level increases.

(5) The peak strengths of specimens DFN0 and DFN90 are in a linear relationship due to the high persistence and defect orientation almost parallel to the critical shear stress, while specimens from the other DFNs having the defect set with a low persistence and a low intersecting angle with the critical shear stress have a bilinear peak strength envelop curve.

The presented results suggest that the DEM investigation can be used as a preliminary study in the engineering application as long as the microproperties of the intact rock matrix and defects/joints can be calibrated accurately. Although the rockmass strength characteristic is studied in this research, some limitations should be improved in the future. Hoek and Brown [51] demonstrate Jaeger's theory is useful in evaluating the strength of the jointed rockmass consisting of several persistent discontinuous planes that intersected with equal angles. The results presented in this study show that the interaction between two defect sets has an apparent characteristic of hierarchy. When the persistence of the "controlling defect set" changes, the mechanical behavior of the rockmass is also influenced. Hence, the mechanical behavior of the rockmass with the different persistence degrees may differ from the results determined by Jaeger's theory. The effect of persistence on the rockmass strength should be studied in the future. Moreover, the results in this study are of a two-dimensional plan analysis, which has limitations in considering the effect of the direction perpendicular to the $2 \mathrm{D}$ plane. Some other effect factors such as the microscale effect of the intact rock also should be considered in a three-dimensional analysis in future research.

\section{Data Availability}

The data used to support the findings of this study are available from the corresponding author upon request.

\section{Conflicts of Interest}

The authors declare that they have no conflicts of interest.

\section{Acknowledgments}

This research work was financially supported by the National Natural Science Foundation of China (51678033). It was also supported by the Open Foundation (2017-02) of China Railway Fifth Survey and Design Institute Group Co., Ltd., and the
Open Foundation (721602) of China Railway Design Group Co., Ltd. All these supports are gratefully acknowledged.

\section{References}

[1] Z. Zhao, L. Jing, and I. Neretnieks, "Particle mechanics model for the effects of shear on solute retardation coefficient in rock fractures," International Journal of Rock Mechanics and Mining Sciences, vol. 52, pp. 92-102, 2012.

[2] D. H. Laubscher and J. Jakubec, "The MRMR rock mass classification for jointed rock masses," in Underground Mining Methods: Engineering Fundamentals and International Case Studies, W. A. Hustrulid and R. L. Bullock, Eds., pp. 474-481, Society of Mining Metallurgy and Exploration, SMME, Englewood, CO, USA, 2001.

[3] N. Bahrani and P. K. Kaiser, "Numerical investigation of the influence of specimen size on the unconfined strength of defected rocks," Computers and Geotechnics, vol. 77, pp. 5667, 2016.

[4] A. Benelfellah, A. Frachon, M. Gratton, M. Caliez, and D. Picart, "Analytical and numerical comparison of discrete damage models with induced anisotropy," Engineering Fracture Mechanics, vol. 121-122, pp. 28-39, 2014.

[5] J. Yang, W. Chen, D. Yang, and J. Yuan, "Numerical determination of strength and deformability of fractured rock mass by FEM modeling," Computers and Geotechnics, vol. 64, pp. 20-31, 2015.

[6] E. Hoek, P. Marinos, and M. Benissi, "Applicability of the geological strength index (GSI) in the Alps," Journal of Glaciology, vol. 6, pp. 161-163, 1998.

[7] N. Barton, "Some new Q-value correlations to assist in site characterisation and tunnel design," International Journal of Rock Mechanics and Mining Sciences, vol. 39, no. 2, pp. 185-216, 2002.

[8] R. Gholami, V. Rasouli, and A. Alimoradi, "Improved RMR rock mass classification using artificial intelligence algorithms," Rock Mechanics and Rock Engineering, vol. 46, no. 5, pp. 1199-1209, 2012.

[9] L. Zhang, "Estimating the strength of jointed rock masses," Rock Mechanics and Rock Engineering, vol. 43, no. 4, pp. 391-402, 2010.

[10] F. E. Heuze, "Scale effects in the determination of rock mass strength and deformability," Rock Mechanics Felsmechanik Mecanique des Roches, vol. 12, no. 3-4, pp. 167-192, 1980.

[11] E. Hoek and M. S. Diederichs, "Empirical estimation of rock mass modulus," International Journal of Rock Mechanics and Mining Sciences, vol. 43, no. 2, pp. 203-215, 2006.

[12] A. Palmström and R. Singh, "The deformation modulus of rock masses-comparisons between in situ tests and indirect estimates," Tunnelling and Underground Space Technology, vol. 16, no. 2, pp. 115-131, 2001.

[13] H. J. Hudson, Engineering Rock Mechanics, Elsevier, Oxford, UK, 1997.

[14] M. Noorian Bidgoli and L. Jing, "Anisotropy of strength and deformability of fractured rocks," Journal of Rock Mechanics and Geotechnical Engineering, vol. 6, no. 2, pp. 156-164, 2014.

[15] M. Laghaei, A. Baghbanan, H. Hashemolhosseini, and M. Dehghanipoodeh, "Numerical determination of deformability and strength of 3D fractured rock mass," International Journal of Rock Mechanics and Mining Sciences, vol. 110, pp. 246-256, 2018.

[16] M. Bidgoli and L. Jing, "Effects of loading conditions on strength and deformability of fractured rocks-a numerical 
study," in Proceedings of EUROCK 2014 ISRM European Regional Symposium, pp. 365-368, Taylor \& Francis Group, Vigo, Spain, May 2014.

[17] K.-B. Min and L. Jing, "Numerical determination of the equivalent elastic compliance tensor for fractured rock masses using the distinct element method," International Journal of Rock Mechanics and Mining Sciences, vol. 40, no. 6, pp. 795816, 2003.

[18] P. A. Cundall and O. D. L. Strack, "A discrete numerical model for granular assemblies," Géotechnique, vol. 29, no. 1, pp. 47-65, 1979.

[19] D. O. Potyondy and P. A. Cundall, "A bonded-particle model for rock," International Journal of Rock Mechanics and Mining Sciences, vol. 41, no. 8, pp. 1329-1364, 2004.

[20] Itasca, PFC 5.0 Documentation, Itasca Inc, Minneapolis, MN, USA, 2015.

[21] L. N. Y. Wong and H. H. Einstein, "Systematic evaluation of cracking behavior in specimens containing single flaws under uniaxial compression," International Journal of Rock Mechanics and Mining Sciences, vol. 46, no. 2, pp. 239-249, 2009.

[22] P. Yin, R. H. C. Wong, and K. T. Chau, "Coalescence of two parallel pre-existing surface cracks in granite," International Journal of Rock Mechanics and Mining Sciences, vol. 68, pp. 66-84, 2014.

[23] D. Huang, D. Gu, C. Yang, R. Huang, and G. Fu, "Investigation on mechanical behaviors of sandstone with two preexisting flaws under triaxial compression," Rock Mechanics and Rock Engineering, vol. 49, no. 2, pp. 375-399, 2015.

[24] S. Wu and X. Xu, "A study of three intrinsic problems of the classic discrete element method using flat-joint model," Rock Mechanics and Rock Engineering, vol. 49, no. 5, pp. 1813-1830, 2016.

[25] X. Fan, R. Chen, H. Lin, H. Lai, C. Zhang, and Q. Zhang, "Experimental Cracking and failure in rock specimen containing combined flaw and hole under uniaxial compression," Advances in Civil Engineering, vol. 2018, Article ID 9818250, 15 pages, 2018.

[26] R. Zhao, H. Lin, and P. Cao, "Strength and failure characteristics of brittle jointed rock-like specimens under uniaxial compression: digital speckle technology and a particle mechanics approach," International Journal of Mining Science and Technology, vol. 28, no. 4, pp. 669-677, 2018.

[27] D. Potyondy, "A flat-jointed bonded-particle material for hard rock," in Proceedings of the 46th U.S. Rock Mechanics/ Geomechanics Symposium, pp. 1-10, Chicago, IL, USA, June 2012.

[28] D. Mas Ivars, M. E. Pierce, C. Darcel et al., "The synthetic rock mass approach for jointed rock mass modelling," International Journal of Rock Mechanics and Mining Sciences, vol. 48, no. 2, pp. 219-244, 2011.

[29] K. Esmaieli, J. Hadjigeorgiou, and M. Grenon, "Estimating geometrical and mechanical REV based on synthetic rock mass models at Brunswick mine," International Journal of Rock Mechanics and Mining Sciences, vol. 47, no. 6, pp. 915-926, 2010.

[30] M. Pierce, D. Mas Ivars, D. Potyondy, and P. A. Cundall, "A synthetic rock mass model for jointed rock," in Rock Mechanics: Meeting Society's Challenges and Demands (1st Canada-U.S. Rock Mechanics Symposium), pp. 341-349, Vancouver, Canada, 2007.

[31] D. Elmo and D. Stead, "An integrated numerical modellingdiscrete fracture network approach applied to the characterisation of rock mass strength of naturally fractured pillars,"
Rock Mechanics and Rock Engineering, vol. 43, no. 1, pp. 3-19, 2010.

[32] P. Wang, T. Yang, T. Xu, M. Cai, and C. Li, "Numerical analysis on scale effect of elasticity, strength and failure patterns of jointed rock masses," Geosciences Journal, vol. 20, no. 4, pp. 539-549, 2016.

[33] Y. Zhang and D. Stead, "Modelling 3D crack propagation in hard rock pillars using a synthetic rock mass approach," International Journal of Rock Mechanics and Mining Sciences, vol. 72, pp. 199-213, 2014.

[34] J. A. Vallejos, A. Brzovic, C. Lopez, L. Bouzeran, and D. Mas Ivars, "Application of the synthetic rock mass approach to characterize rock mass behavior at the El Teniente mine, Chile," in Proceedings of the 3nd International FLAC/DEM Symposium, Itasca International Inc., Hangzhou, China, October 2013.

[35] B. A. Poulsen and D. P. Adhikary, "A numerical study of the scale effect in coal strength," International Journal of Rock Mechanics and Mining Sciences, vol. 63, pp. 62-71, 2013.

[36] A. J. Li, M. J. Cassidy, Y. Wang, R. S. Merifield, and A. V. Lyamin, "Parametric Monte Carlo studies of rock slopes based on the Hoek-Brown failure criterion," Computers and Geotechnics, vol. 45, pp. 11-18, 2012.

[37] M. Bahaaddini, G. Sharrock, and B. K. Hebblewhite, "Numerical investigation of the effect of joint geometrical parameters on the mechanical properties of a non-persistent jointed rock mass under uniaxial compression," Computers and Geotechnics, vol. 49, pp. 206-225, 2013.

[38] A. H. Ghazvinian, M. J. Azinfar, and R. Geranmayeh Vaneghi, "Importance of tensile strength on the shear behavior of discontinuities," Rock Mechanics and Rock Engineering, vol. 45, no. 3, pp. 349-359, 2012.

[39] X. Li, H. Konietzky, X. Li, and Y. Wang, "Failure pattern of brittle rock governed by initial microcrack characteristics," Acta Geotechnica, vol. 15, no. 5, p. 21, 2019.

[40] A. Basu, D. A. Mishra, and K. Roychowdhury, "Rock failure modes under uniaxial compression, Brazilian, and point load tests," Bulletin of Engineering Geology and the Environment, vol. 72, no. 3-4, pp. 457-475, 2013.

[41] N. Erarslan, Z. Z. Liang, and D. J. Williams, "Experimental and numerical studies on determination of indirect tensile strength of rocks," Rock Mechanics and Rock Engineering, vol. 45, no. 3, pp. 739-751, 2011.

[42] K. Li, Y. Cheng, and X. Fan, "Roles of model size and particle size distribution on macro-mechanical properties of Lac du Bonnet granite using flat-joint model," Computers and Geotechnics, vol. 103, pp. 43-60, 2018.

[43] U. Castro-Filgueira, L. R. Alejano, J. Ivars, and D. Mas Ivars, "Sensitivity analysis of the micro-parameters used in a PFC analysis towards the mechanical properties of rocks," Procedia Engineering, vol. 191, pp. 488-495, 2017.

[44] M. Bahaaddini, P. C. Hagan, R. Mitra, and B. K. Hebblewhite, "Parametric study of smooth joint parameters on the shear behaviour of rock joints," Rock Mechanics and Rock Engineering, vol. 48, no. 3, pp. 923-940, 2015.

[45] N. Barton, "Shear strength criteria for rock, rock joints, rockfill and rock masses: problems and some solutions," Journal of Rock Mechanics and Geotechnical Engineering, vol. 5, no. 4, pp. 249-261, 2013.

[46] A. Khani, A. Baghbanan, and H. Hashemolhosseini, "Numerical investigation of the effect of fracture intensity on deformability and REV of fractured rock masses," International Journal of Rock Mechanics and Mining Sciences, vol. 63, pp. 104-112, 2013. 
[47] Z. T. Bieniawski, "The effect of specimen size on compressive strength of coal," International Journal of Rock Mechanics and Mining Sciences \& Geomechanics Abstracts, vol. 5, no. 4, pp. 325-335, 1968.

[48] F. D. Patton, Multiple Modes of Shear Failure in Rock and Related Material, University of Illinois, Urbana, IL, USA, 1966.

[49] Y. M. Alshkane, A. M. Marshall, and L. R. Stace, "Prediction of strength and deformability of an interlocked blocky rock mass using UDEC," Journal of Rock Mechanics and Geotechnical Engineering, vol. 9, no. 3, pp. 531-542, 2017.

[50] J. C. Jaeger, N. G. W. Cook, and R. Zimmerman, Fundamentals of Rock Mechanics, Wiley Blackwell, Hoboken, NJ, USA, 2007.

[51] E. Hoek and E. Brown, "Empirical strength criterion for rock masses," Journal of Geotechnical Engineering-ASCE, vol. 106, pp. 1013-1035, 1980. 